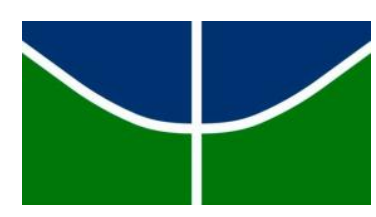

UNIVERSIDADE DE BRASÍLIA

FACULDADE DE AGRONOMIA E MEDICINA VETERINÁRIA PROGRAMA DE PÓS-GRADUAÇÃO EM CIÊNCIAS ANIMAIS

CARACTERIZAÇÃO DO CICLO ESTRAL DE ÉGUAS DA RAÇA PANTANEIRO E CAMPEIRO NO PLANALTO CENTRAL

JESSICA NERI NASCIMENTO

DISSERTAÇÃO DE MESTRADO EM CIÊNCIAS ANIMAIS BRASÍLIA/DF

NOVEMBRO DE 2014 
UNIVERSIDADE DE BRASÍLIA

FACULDADE DE AGRONOMIA E MEDICINA VETERINÁRIA

CARACTERIZAÇÃO DO CICLO ESTRAL DE ÉGUAS DA RAÇA PANTANEIRO E CAMPEIRO NO PLANALTO CENTRAL

Aluna: Jessica Neri Nascimento

Orientador: Prof. Dr. Rodrigo Arruda de Oliveira

Co-orientador: Dr. Alexandre Floriani Ramos

DISSERTAÇÃO DE MESTRADO EM CIÊNCIAS ANIMAIS

BRASÍLIA/DF

NOVEMBRO DE 2014 


\section{REFERÊNCIA BIBLIOGRÁFICA E CATALOGAÇÃo}

\section{NASCIMENTO, J.N. Caracterização do ciclo estral de éguas da raça Pantaneiro e}

Campeiro no Planalto Central. Brasília: Faculdade de Agronomia e Medicina Veterinária, Universidade de Brasília, 2014, 53p. Dissertação de Mestrado.

Documento formal, autorizando reprodução desta dissertação de mestrado para empréstimo ou comercialização, exclusivamente para fins acadêmicos, foi passado pelo autor à Universidade de Brasília e acha-se arquivado na Secretaria do Programa.

Nenhuma parte desta dissertação de mestrado pode ser reproduzida sem a autorização por escrito do autor ou do seu orientador. Citações são estimuladas desde que citadas às fontes.

\section{FICHA CATALOGRÁFICA}

NASCIMENTO, J.N. Caracterização do ciclo estral de éguas da raça Pantaneiro e Campeiro no Planalto Central. Brasília: Faculdade de Agronomia e Medicina Veterinária, Universidade de Brasília, 2014, 53p. Dissertação (Mestrado em Ciências Animais) Faculdade de Agronomia e Medicina Veterinária da Universidade de Brasília, 2014.

1. Raça Pantaneiro 2. Raça Campeiro 3. Dinâmica Folicular. 4. Conservação

I. De Oliveira, Rodrigo Arruda, orientador. II. Ramos, Alexandre Floriani, co- orientador. III. Título. 
UNIVERSIDADE DE BRASÍLIA

FACULDADE DE AGRONOMIA E MEDICINA VETERINÁRIA

CARACTERIZAÇÃO DO CICLO ESTRAL DE ÉGUAS DA RAÇA PANTANEIRO E CAMPEIRO NO PLANALTO CENTRAL

JESSICA NERI NASCIMENTO

DISSERTAÇÃO DE MESTRADO SUBMETIDA AO PROGRAMA DE PÓS-GRADUAÇÃO EM CIÊNCIAS ANIMAIS COMO PARTE DOS REQUISITOS NECESSÁRIOS À OBTENÇÃO DO GRAU DE MESTRE EM CIÊNCIAS ANIMAIS.

APROVADA POR:

RODRIGO ARRUDA DE OLIVEIRA, DOUTOR (UnB - DF)

FABRÍCIO DESCONSI MOZZAQUATRO, Doutor (UNIPAMPA- RS)

CARLOS FREDERICO MARTINS, Doutor (EMBRAPA - DF)

BRASÍLIA/DF, 28 de Novembro de 2014. 


\section{AGRADECIMENTOS}

A Deus que é o sentido da vida;

A minha mãe que não mede esforços para me fazer feliz todos os dias;

Ao meu pai que é meu porto seguro e o meu maior exemplo de vitória;

Ao "meu Maca", que sempre esteve sei que sempre estará ao meu lado com uma palavra de apoio;

A minha querida amiga Cida Vidal que foi a primeira a me incentivar a seguir nesta jornada.

Aos amigos que sempre estiveram ao meu lado.

A todos da Fazenda Sucupira - Embrapa que sempre me receberam de braços

abertos.

Ao meu orientador Rodrigo, que topou enfrentar este desafio comigo.

Ao Dr. Alexandre Floriani pela paciência e colaboração.

Ao CNPq pela bolsa de estudo.

A todos que contribuíram para que este projeto se realizasse. 


\section{ÍNDICE}

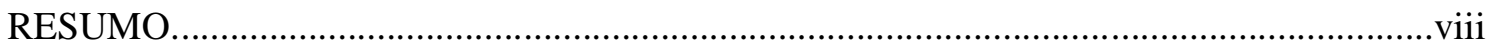

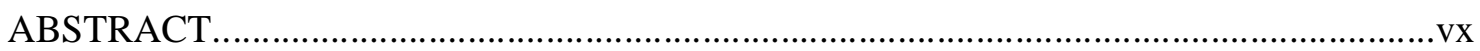

LISTA DE SÍMBOLOS E ABREVIAÇÕES.................................................................

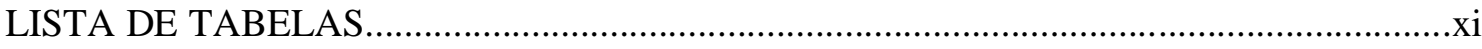

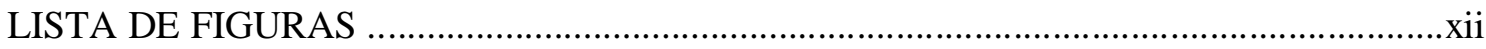

CAPÍTULO 1 - INTRODUÇÃO E REVISÃO DE LITERATURA...................................... 1

1 INTRODUÇÃO

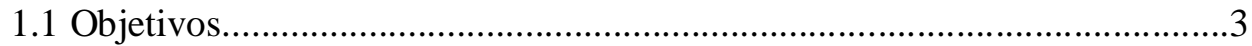

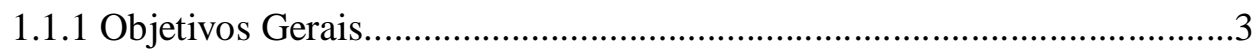

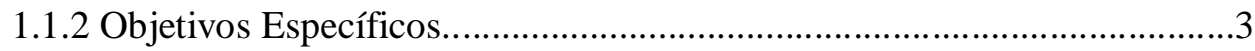

2 REVISÃO DE LITERATURA..............................................................

2.1 Origem e Características raciais do cavalo Pantaneiro.................................4

2.2 Origem e Características raciais do cavalo Campeiro...................................5

2.3 Fisiologia reprodutiva dos equinos........................................................6

3 REFERÊNCIAS BIBLIOGRÁFICAS.....................................................10

CAPÍTULO 2 - DINÂMICA FOLICULAR OVARIANA DE ÉGUAS DA RAÇA

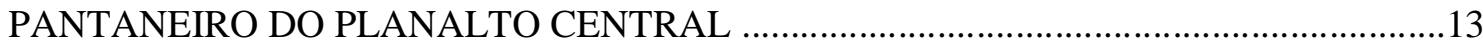

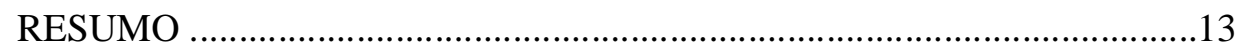

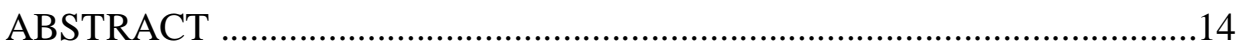

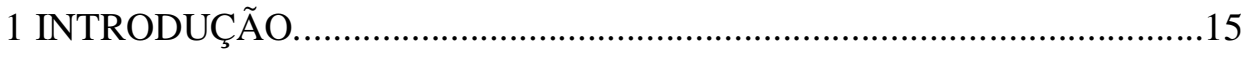

2 MATERIAIS E MÉTODOS................................................................15

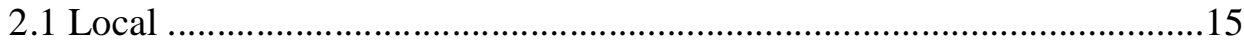

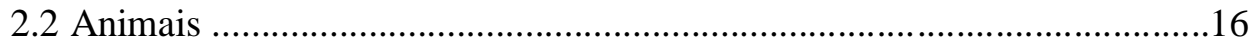

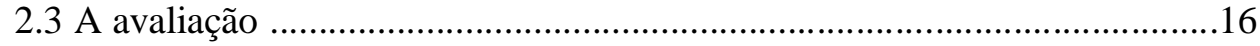

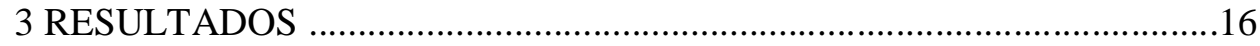

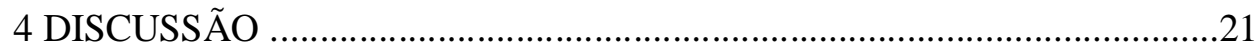

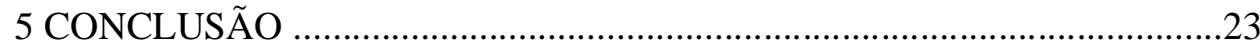

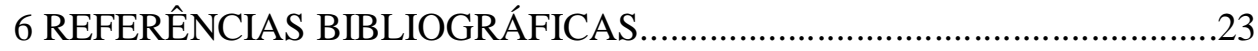

CAPÍTULO 3 - DINÂMICA FOLICULAR OVARIANA DE ÉGUAS DA RAÇA

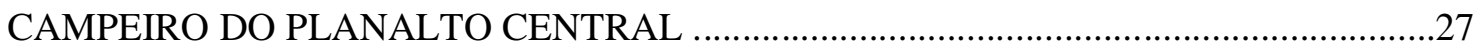

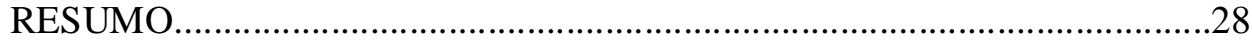




ABSTRACT

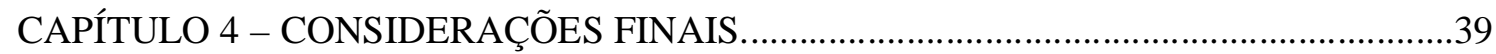




\title{
CARACTERIZAÇÃo DO CICLO ESTRAL DE ÉGUAS DA RAÇA PANTANEIRO E CAMPEIRO NO PLANALTO CENTRAL
}

\author{
Jessica Neri Nascimento \\ Prof. Dr. Rodrigo Arruda de Oliveira \\ Dr. Alexandre Floriani Ramos \\ Brasília, DF
}

RESUMO

O cavalo Campeiro e Pantaneiro são raças localmente adaptadas que possuem importantes características adaptativas como rusticidade, resistência a longas caminhadas e capacidade de tração. Com o intuito de conservação deste recurso genético e visando a seleção e o melhoramento genético destas raças diversos estudos estão sendo realizados com estes animais. Neste sentido, objetivou-se com este Experimento avaliar as principais características do ciclo estral das éguas da raça Campeiro e Pantaneiro nas diferentes estações do ano. Foram utilizadas seis éguas de cada raça $(n=6)$. Um ciclo estral de cada égua foi acompanhado por palpação retal e ultrassonografia em cada uma das diferentes estações do ano. As raças foram separadas em capítulos. O capítulo 2 mostra que para as éguas da raça Pantaneiro, houve diferença na duração do ciclo estral. Os meses de Outono e Inverno apresentaram o ciclo estral mais prolongado quando comparados aos meses de Primavera e Verão. Sobre dia de divergência e tamanho folicular, dia de dominância e tamanho folicular, tamanho do folículo pré ovulatório e tamanho da estrutura lútea nas éguas Pantaneiras não houve diferença entre as estações do ano. A maioria das éguas Pantaneiras se mantiveram cíclicas durante as estações do ano no Outono (06/06), Inverno (04/06), Primavera (05/06) e Verão (06/06). O capítulo 3 avalia a raça Campeiro, a duração do ciclo estral das éguas foi menor nos meses de Outono e Verão quando comparado com os meses de Inverno e Primavera $(\mathrm{P} \leq 0,05)$. $\mathrm{O}$ dia da divergência folicular para raça Campeiro foi mais tardio no Inverno e Primavera do que no Outono e Verão $(\mathrm{P} \leq 0,05)$. E o dia da dominância foi mais tardio no Outono e Primavera que no Inverno e Verão $(\mathrm{P} \leq 0,05)$. Para os demais parâmetros avaliados não houve diferença $(\mathrm{P}>0,05)$. A maior quantidade de éguas Campeiras cíclicas foi no Outono (06/06), seguido pela Primavera e Verão (05/06) e o Inverno mostrou a menor quantidade de éguas em atividade reprodutiva (04/06). As éguas da raça Pantaneiro e Campeiro apresentam características do ciclo estral similares a de éguas de outros raças. Possuem ondas foliculares maiores e primárias e mostraram pouca influência sazonal já que a maioria dos animais, de ambas as raças, se mantiveram cíclicos em todas as estações do ano.

Palavras-chave: Ciclo estral; dinâmica folicular; éguas; estações do ano. 


\title{
CHARACTERISTICS OF OESTRUS CYCLE IN THE PANTANEIRO AND CAMPEIRO MARES ON CENTRAL PLATEOU
}

\author{
Jessica Neri Nascimento \\ Prof. Dr. Rodrigo Arruda de Oliveira \\ Dr. Alexandre Floriani Ramos \\ Brasília, DF
}

\begin{abstract}
The Campeiro and Pantaneiro horse are locally adapted breeds that have important adaptive traits such as rusticity, long walks resistance and traction capacity. With the conservation purpose of this genetic resource and in order to select and the genetic improvement of these breeds several studies are being conducted with these animals. In this sense, the objective was to evaluate with this experiment the main features of the estrous cycle of mares and Campeiro Pantaneiro race in different seasons. Six were selected mares of each race $(n=6)$. A estrous cycle of each mare was accompanied by rectal palpation and ultrasonography in each of the different seasons. The races were separated into chapters. Chapter 2 shows that for mares Pantaneiro breed was no difference in the estrous cycle. The months of autumn and winter have submitted the most protracted estrous cycle when compared to the months of spring and summer. About the day of divergence and follicular size, day of dominance and follicular size, pre ovulatory follicle size and size of luteal structure in mares not was no difference between the seasons. Most Pantaneiro mares remained cyclical during the seasons in autumn (06/06), winter (04/06), Spring (05/06) and summer (06/06). Chapter 3 evaluates the Campeiro breed, the length of the estrous cycle of the mares was lower in the months of autumn and summer compared to the winter months and spring $(\mathrm{P} \leq 0.05)$. The day of follicle deviation for Campeiro was slower in winter and spring than in autumn and summer $(\mathrm{P} \leq$ 0.05). And the day of dominance was later in the autumn and spring than in winter and summer $(\mathrm{P} \leq 0.05)$. For other parameters there was no difference $(\mathrm{P}>0.05)$. The largest amount of cyclic mares was foraging in autumn (06/06), followed by the spring and summer $(05 / 06)$ and Winter showed the least amount of reproductive activity in mares (04/06). The mares of the Pantanal and Campeiro race have similar estrous cycle characteristics of the other breeds mares. Have larger and primary follicular waves and showed little seasonal influence since the majority of the animals of both breeds, remained cyclical in all seasons. Keywords: estrous cycle; follicular dynamics; mares; seasons.
\end{abstract}




\section{LISTA DE ABREVIAÇÕES E SÍMBOLOS}

$\%:$ Porcentagem

ABCCP: Associação Brasileira dos Criadores de Cavalo Pantaneiro

ABRACCC: Associação Brasileira dos Criadores de Cavalo Campeiro

CL: Corpo Lúteo

ECC: Escore de Condição Corporal

FSH: Hormônio Folículo Estimulante

GnRH: Hormônio Liberador de Gonadotrofinas

Kg: Quilograma

LH: Hômonio Luteinizante

m: Metro

ml: Mililitro

mm: Milímetro

${ }^{\circ} \mathrm{C}$ : Graus Celsius

$\mathrm{T}$ : Temperatura

UR: Umidade relativa

MHz: Megahertz 


\section{LISTA DE TABELAS}

Tabela 01. Características do ciclo estral de éguas Pantaneiro criadas no Planalto Central nas diferentes estações do ano de 2012 30

Tabela 02. Características do ciclo estral de éguas Campeiro criadas no Planalto Central nas diferentes estações do ano de 2012 


\section{LISTA DE FIGURAS}

Figura 01. Padrão racial do cavalo Pantaneiro 5

Figura 02. Padrão racial do cavalo Campeiro

Figura 03. Curva de crescimento folicular de éguas Pantaneiro criadas no Planalto Central nos meses de Outono 18

Figura 04. Curva de crescimento folicular de éguas Pantaneiro criadas no Planalto Central durante o Inverno 19

Figura 05. Curva de crescimento folicular de éguas Pantaneiro criadas no Planalto Central durante a Primavera 20

Figura 06. Curva de crescimento folicular de éguas Pantaneiro criadas no Planalto Central durante o Verão 20

Figura 07. Edema uterino grau 3 20

Figura 08. Curva de crescimento folicular de éguas Campeiro criadas no Planalto Central durante o Outono 33

Figura 09. Curva de crescimento folicular de éguas Campeiro criadas no Planalto Central durante a Inverno 33

Figura 10. Curva de crescimento folicular de éguas Campeiro criadas no Planalto Central durante o Primavera 34

Figura 11. Curva de crescimento folicular de éguas Campeiro criadas no Planalto Central durante o Verão 34

Figura 12. Edema uterino grau 3 


\section{CAPÍTULO 1}

INTRODUÇÃO E REVISÃO DE LITERATURA 


\section{INTRODUÇÃO}

O Brasil possui diversas raças de animais domésticos que se desenvolveram a partir de raças trazidas pelos colonizadores portugueses após o descobrimento. Ao longo de séculos, estas raças foram submetidas à seleção natural em determinados ambientes, a ponto de apresentarem características específicas de adaptação (CORRÊA FILHO, 1973; BECK, $1985)$.

Estas raças aqui desenvolvidas passaram a ser conhecidas como localmente adaptadas e devido a cruzamentos indiscriminados com outros animais de raças exóticas muitas chegaram a ser extintas ou reduziram drasticamente o número de exemplares (SANTOS et al, 1995). Uma comparação entre espécies revela que os equinos (23\%), seguidos pelos coelhos (20\%), suínos (18\%) e bovinos (16\%), são as espécies de mamíferos com mais altas proporções de raças em situação de risco de extinção (EMBRAPA, 2010).

Tendo ciência do alto valor genético destes animais, principalmente relacionado às características adaptativas, a necessidade de conservação e exploração dos recursos genéticos é reforçada.

Segundo Mariante et al. (2011), existem diferentes formas de conservação de recursos genéticos animais: in situ, a partir da implantação de núcleos de conservação nas regiões de origem dessas raças; conservação ex situ in vivo, na qual os animais são conservados fora de seu habitat original, ou seja, longe do local onde eles foram submetidos à ação da seleção natural; e conservação ex situ in vitro, que se baseia na utilização de técnicas criogênicas de armazenamento de material genético como sêmen e embriões.

Os equinos Campeiros e Pantaneiros estão inseridos neste cenário como raças localmente adaptadas que possuem núcleos de conservação ex situ in vivo, sendo um deles a Fazenda Sucupira, pertencente a Embrapa Recursos Genéticos e Biotecnologia em Brasília DF.

A par de que a reprodução destas raças é parte fundamental no processo de conservação e melhoramento genético, objetivou-se avaliar as características do ciclo estral de éguas da raça Pantaneiro e Campeiro no Planalto Central.

Acredita-se que devido a suas características adaptativas e rústicas estes animais se assemelhem a animais cruzados ou mestiços e sofram pouca interferência da sazonalidade no ciclo estral. 


\subsection{OBJETIVOS}

\subsubsection{Objetivos gerais}

Caracterizar os principais eventos fisiológicos relacionados ao ciclo estral, que ocorrem nas raças Pantaneiro e Campeiro durante cada uma das estações do ano.

\subsubsection{Objetivos específicos}

Caracterizar a dinâmica folicular destacando as fases de seleção, desvio folicular, dominância folicular e estágio pré ovulatório nas raças Pantaneiro e Campeiro.

Avaliar o crescimento e regressão da estrutura folicular e verificar seu comportamento durante o ciclo estral.

Avaliar a morfoecogenicidade uterina durante o estro e a tonicidade uterina no diestro.

Avaliar o ciclo estral e correlacionar com a interferência da sazonalidade. 


\section{REVISÃO DE LITERATURA}

\subsection{Características raciais do cavalo Pantaneiro}

A origem desta raça está relacionada a ocupação da parte central da América do Sul e é provavelmente oriundo de cruzamentos de cavalos de origem lusitana (Céltico, Barba e Andaluz), do Crioulo Argentino e do Acabe (SANTOS et al. 1992). Balieiro (1971) indica como locais de formação da raça as cidades de: Santo Antônio de Leverger, Barão de Melgaço, Nossa Senhora do Livramento, Poconé, Cárceres, Corumbá e Aquidauana todos no Estado de Mato Grosso.

Por volta de 1900, com o objetivo de aumentar o porte e melhorar alguns aspectos da conformação racial foram realizados cruzamentos com animais de origem direta com o Puro Sangue Inglês. Já em 1973, Corrêa Filho identificou dois principais fenótipos dentro da raça, o cavalo da Bala e o cavalo Mimoseano. A união destes fenótipos formou a raça atual.

Com o desenvolvimento da pecuária no Pantanal Mato grossense, houve a necessidade de exploração de locais com pouco acesso aos meios de transporte comuns, como carros, caminhões e até mesmo navios, lanchas ou canoas de pequeno porte (MISSERANI et al, 2002).

Desta forma, surgiu à utilização do cavalo Pantaneiro como meio de transporte e como um facilitador para o uso de recursos. Ainda nos dias de hoje o cavalo Pantaneiro auxilia no traçado de canoas para que sejam transportados alimentos, insumos e outros materiais para os recantos mais isolados durante a longa época de chuva na região (SANTOS et al, 1995).

Este animal é essencial na lida com o gado, sendo capaz de trotar por períodos prolongados em áreas alagadas. Possui cascos resistentes, capaz de permanecer por grande parte do ano com os membros submersos. Apresentam também a capacidade de pastoreio dentro da água, muitas vezes com as narinas submersas (SANTOS et al, 2002).

Por tantas características de adaptação favoráveis ao local de criação, o cavalo Pantaneiro possui papel de grande relevância para que o homem pantaneiro possa permanecer no campo mesmo com as difíceis condições oferecidas, e mais, trouxe ao homem pantaneiro facilidades para a produção de alimento para consumo e para suas criações (MISSERANI et al, 2002).

Em 1972 foi fundada a Associação Brasileira de Criadores de Cavalo Pantaneiro (ABCCP) desde então, a pressão de seleção aumentou e hoje, o cavalo Pantaneiro 
possui uma extensa árvore genealógica que interessa não somente ao Pantaneiro Mato grossense, mas também a milhares de criadores espalhados pelo Brasil que buscam animais versáteis e com importantes características de rusticidade (ABCCP, 2014).

A padronização da raça estipulada pela ABCCP apresenta o cavalo Pantaneiro como de porte médio, com altura de cernelha mínima de 1,35 m para fêmeas e 1,40 m para machos, peitoral profundo e amplo, pescoço musculoso, cauda erguida ao galope e pelagem variada, a associação não aceita registro de animais com pelagem albina (Figura 1).

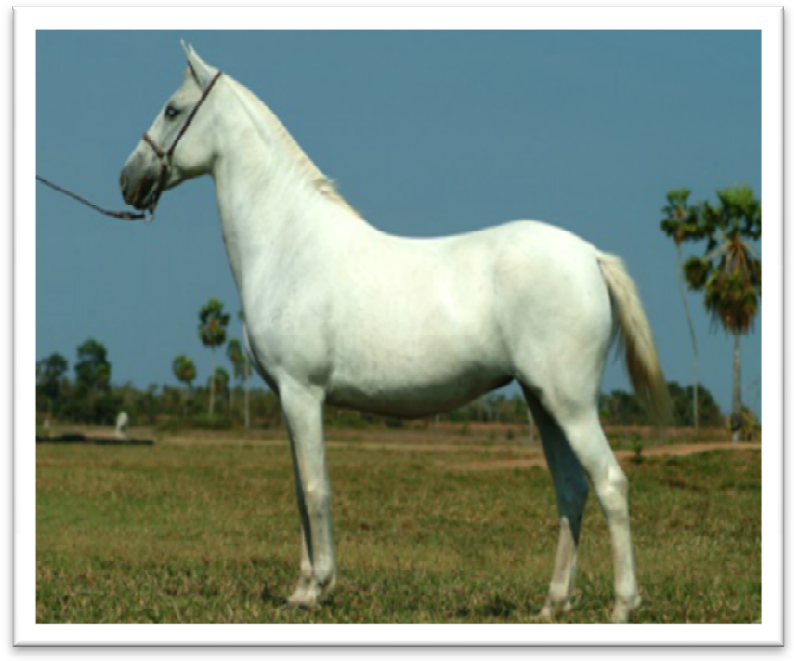

Figura 01. Padrão racial do cavalo Pantaneiro

Fonte: Associação Brasileira dos Criadores de Cavalo

Pantaneiro, 2014

\subsection{Origem e características raciais do cavalo da raça Campeiro}

O cavalo Campeiro provavelmente é originado de animais trazidos por expedições Espanholas em 1541, nesta ocasião Alvar Nuñes seguiu do litoral de Santa Catarina até o Paraguai. Duzentos anos depois da expedição foi notificada a presença de equinos selvagens no planalto catarinense, planalto do Rio Grande do Sul e sudeste do Paraná, destas localidades então, surgiu a denominação de Marchador das Araucárias (ARAÚJO, 1990; ABCCC, 2012).

Visando obter mais velocidade e beleza, foram feitos cruzamentos com cavalos de sangue Árabe. Alguns anos mais tarde, devido ao andamento confortável e com bom rendimento, a resistência a longas caminhadas, beleza e funcionalidade, fazendeiros da região de Lages e Curitibanos - SC começaram a valorizar a raça. 
E em 1976 foi fundada a Associação Brasileira dos Criadores de Cavalo Campeiro (ABRACCC). O padrão morfológico da raça foi caracterizado como um cavalo de pequeno a médio porte, com altura máxima de 1,54 m para machos e 1,52 $\mathrm{m}$ para fêmeas, pescoço delicado bem inserido na cabeça, orelhas medianas e pelagens variadas, sendo que pampa e albino não são reconhecidas pela Associação.

A associação possui atualmente somente 990 fêmeas e 140 machos registrados. Com a área de criação restrita aos municípios de Lajes e Curitibanos - SC existe uma forte tendência para a redução deste quantitativo.

De acordo com dados fornecidos pela FAO (1992), ao estabelecer o status de risco de uma população em função da quantidade de fêmeas em reprodução, a raça Campeiro está em situação de perigo (Figura 2).

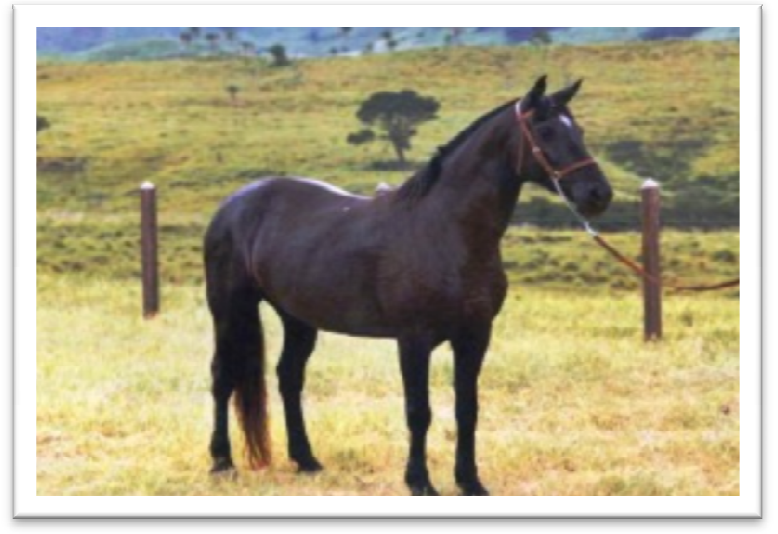

Figura 02. Padrão racial do cavalo Campeiro

Fonte: Associação Brasileira dos Criadores de Cavalo

Campeiro, 2014

\subsection{Fisiologia reprodutiva dos equinos}

O ovário dos mamíferos é um órgão complexo, composto por uma série de células diferenciadas, e comumente é delimitado em 2 regiões, a medular que na maioria das espécies, com exceção a equina, consiste na porção interna e é composta por tecido conjuntivo, nervos, artérias e veias; e a região cortical que contém o corpo lúteo, albicans e os folículos em diversos estágios de desenvolvimento (LEITÃO et al, 2009).

Os fatores produzidos pelos diferentes tipos celulares e os nutrientes e hormônios provenientes da corrente sanguínea criam um sistema complexo que regula as funções dos ovários, a produção de gametas e hormônios (ERICKSON e SHIMASAKI, 2003) 
Ainda durante a vida fetal, ocorre a diferenciação das células primordiais em gametas femininos ou masculinos, no caso da fêmea, em ovócitos que irão se desenvolver juntamente com o crescimento inicial dos folículos. No entanto, apenas uma pequena porção de folículos espécie específicos são selecionados para chegar até a vida adulta e finalmente ovular (CUNNINGHAM,2008)

Foi identificado que nas éguas existem dois tipos de ondas foliculares: a onda maior, que se refere a um conjunto de folículos que inicialmente exibe crescimento sincronizado, sucedido pelo crescimento preferencial de apenas um, ocasionalmente dois folículos (GINTHER, 1989). Esta pode ser dividida em onda primária e secundária, em que a primária geralmente tem início na metade do diestro e dá origem ao folículo ovulatório ( $\geq 35$ mm). E a secundária que emerge no início do estro e usualmente resulta na formação de grandes folículos anovulatórios $(\geq 20 \mathrm{~mm}$ ) ou, as chamadas ovulações de diestro. E, finalmente, ondas que não apresentam folículos dominantes são classificadas como ondas menores (GINTHER, 1992).

A dinâmica folicular relata o crescimento folicular, a regressão luteal e faz relação destes eventos com os hormônios envolvidos. O primeiro evento a ocorrer é a emergência folicular que é o recrutamento de folículos sensíveis ao hormônio folículo estimulante (FSH), durante este momento o folículo possui o menor diâmetro observado, que geralmente é de \pm 6 mm (DRIANCOURT, 2001; GINTHER,2000).

Após a emergência, a concentração de FSH segue crescente levando todos os folículos a uma fase de crescimento rápida de contínua por 3 dias, neste instante o maior folículo antral tem aproximadamente $13 \mathrm{~mm}$ (GASTAL et al, 1993).

Os níveis de FSH começam a declinar (GINTHER et al, 2002) e 3 dias após ocorre o desvio folicular, ou dia da divergência folicular, onde o maior folículo tende a ter uma taxa de crescimento maior que a dos demais.

Logo adiante o folículo dominante passa a produzir um hormônio inibidor da secreção de FSH, a Inibina, mas mesmo com baixas concentrações de FSH, o dominante é capaz de continuar a crescer numa proporção maior que seu competidor devido a maior quantidade de receptores (CUNNIGHAM, 2004; GINTHER et al, 2002).

Segundo Ginther 2000, o primeiro folículo a alcançar $20 \mathrm{~mm}$ se torna o dominante, em $93 \%$ dos ciclos observados $(n=29)$. Os folículos que regridem são recobertos por células inflamatórias e a área é preenchida por tecido conjuntivo (CUNNIGHAM, 2004).

A secreção de hormônio luteinizante (LH) aumenta próxima a divergência folicular e segue crescente até o momento da ovulação em que as células estrogênicas são 
substituídas por células luteais, mesmo com sua produção surgindo antes da divergência não sabemos ao certo como age durante o desvio folicular.

Diferente de outras espécies domésticas, em éguas não há um pico pré ovulatório de LH, no entanto, a concentração de LH é mantida elevada por alguns dias até a ovulação (GASTAL et al 1997, 1999; GINTHER, 2000; AURICH, 2011).

O corpo lúteo (CL) equino não sobressai para a parte externa do ovário, e é composto por células luteais e não luteais (KIMURA et al, 2005), no entanto, diferentemente das demais espécies as células luteais equina são originas das células da Granulosa do folículo pré ovulatório e não das Tecais. Durante a ovulação as células Tecais estão em vários estágios e posteriormente são substituídas por fibroblastos (VAN NIEKERK et al, 1975).

A concentração de progesterona aumenta imediatamente após a ovulação, mas seu nível máximo é atingido na oitavo dia após isto segue decrescente até o momento da luteólise que ocorre por volta do décimo quarto dia (ROBERTO da COSTA et al, 2005).

Pelo acompanhamento ultrassonográfico observou-se que há uma redução da área lútea a partir do quarto dia, no entanto o volume de células excretoras aumenta até atingir seu volume máximo concomitante com a melhor visualização da estrutura por volta do terceiro dia pós-ovulação (NIEKERK et al, 1975; AGUILAR et al, 2006; GINTHER et al, 2007);

Em éguas, a secreção folicular de estrógeno atinge o pico um ou dois dias antes da ovulação e depois, declina até atingir níveis básicos no diestro e, ao contrário do que ocorre em outras espécies, a administração de estrógenos não leva a onda pré-ovulatória de LH nem causa supressão no LH (McKINNON e VOSS, 1992).

Evans (2003) cita um possível feedback positivo do estrógeno sobre as concentrações de LH, estimulando o crescimento do folículo dominante logo após o desvio.

Em estudo realizado por Gastal et al, (1999a) foi observado que o aumento médio da concentração de estradiol no líquido intrafolicular do maior folículo e na circulação sistêmica ocorreu quando o diâmetro folicular atingiu em torno de $20 \mathrm{~mm}$, entretanto o dia da divergência só ocorreu mais tarde, quando o maior folículo atingiu $25 \mathrm{~mm}$.

Associando os resultados anteriores aos achados ultrassonográficos Gastal et al, (1999a) mostraram que o aumento da produção de estradiol está relacionada com uma série de alterações na parede folicular do maior folículo um dia antes do momento da divergência.

A fêmea equina é classificada como poliéstrica estacional, em dias com maior incidência de luz a glândula pineal é estimulada e inibe a síntese de melatonina, que funciona 
como estímulo para as atividades hipotalâmicas (HAFEZ et al, 1995), logo, o ciclo reprodutivo é dividido em competência sexual (estação reprodutiva) que ocorre durante a Primavera/Verão, e incompetência sexual (anestro sazonal) no Outono/Inverno.

A fase que antecede a estação reprodutiva é chamada de fase de transição de Primavera (Agosto a Setembro) alguns animais começam a ciclar, mas os cios são prolongados e até anovulatórios. A fase que segue pós-estação reprodutiva é chamada de transição de Outono (Março a Abril), os ciclos são prolongados até que cheguem ao anestro (OLIVEIRA E SOUZA, 2003).

O ciclo estral na égua dura em média 21 dias ( \pm 3 dias), sendo 7 dias de estro (fase folicular) e os demais pertencentes ao diestro (fase luteal). A ovulação ocorre por volta de 48 a 24 horas antes do final da fase folicular. (LINDEBERG et al, 1992; GINTHER, 1979). 


\section{REFERÊNCIA BIBLIOGRÁFICA}

AGUILAR, J.; FRASER, H.M.; WILSON, H.; CLUTTON, E.; SHAW, D.J.; WATSON, E.D. Temporal relationship between proliferating and apoptotic hormone-producing and endothelial cells in the equine corpus luteum. Reproduction, v. 132, p.111-118, 2006.

ARAÚJO, R.V. Os Jesuítas dos sete povos. Canoas: La Salle, 467p, 1990.

AURICH, C. Reproductive cycles of horses. Animal Reproduction Science, v.124, p.220$228,2011$.

BALIEIRO, E. Subsídios ao estudo do cavalo pantaneiro. Anuário CCCN, São Paulo, p.59$65,1971$.

BECK. S.L. Eqüinos - ração, manejo e equitação. Ed: São Paulo, 581p, 1985.

BEG M.A; GINTHER O.J. Follicle selection in cattle and horse: role of intrafollicular factors. Journal of Reproduction and Fertility, v.132, p.365-377, 2006.

CORRÊA FILHO, E.A. O cavalo pantaneiro. Revista Medicina Veterinária, v.8, n.3, p.395$412,1973$.

CUNNIGHAM, J.G.; BRADLEY, K. Tratado de fisiologia veterinária, Editora: Elsevier Brasil, $4^{\circ}$ Edição, p.474 - 476, 2008.

DRIANCOURT, M. A. Regulation of ovarian follicular dynamics in farm animals: implications for manipulation of reproduction. Theriogenology, v. 55, p. 1211-1239, 2001.

EMBRAPA RECURSOS GENÉTICOS E BIOTECNOLOGIA. Situação mundial dos recursos genéticos animais para agricultura e alimentação - versão resumida, 2010.

EVANS A.C.O. Characteristics of ovarian follicle development in domestic animals. Reproduction of Domestic Aniamals, v.38, p.240-246, 2003. 
GASTAL E.L; GASTAL M.O; BERGFELT D.R. Role of diameter differences among follicles in selection of a future dominant follicle in mares. Biology of Reproduction v.57, p. $1320-1327,1997$.

GINTHER O. J. Reproductive biology of the mares basic and apllied aspects, Ed. Equiservices, $2^{\circ}$ Edição, p. 176 - 185, 1992.

GINTHER O.J Temporal association among ovarian events in cattle during oestrous with two and three follicular waves. Journal of Reproduction and Fertility, p. 223 - 230, 1989.

GINTHER O.J. Selection of the dominant follicle in cattle and horses. Animal Reproduction Science, v.60, p.61-79, 2000.

GINTHER O.J; GASTAL E.L.; GASTAL M.O.; BEG M.A. Regulation of circulating gonadotropins by the negative effects of ovarian hormones in mares. Biology of Reproduction, v.73, p.315-323, 2005.

GINTHER, O.J.; GASTAL, E.L.; GASTAL, M.O.; UTT, M.D.; BEG, M.A. Luteal blood flow and progesterone production in mares. Animal Reproduction Science, v. 99, p. 213$220,2007$.

HODGES, J. The management of global animal genetic resources. Proceedings of an FAO Expert Consultation, 263p., Itália, 1992. Disponível em http://www.fao.org/docrep/006/t0665e/t0665e00.HTM

KIMURA, J.; HIRANO, Y.; TAKEMOTO, S.; NAMBO, Y.; ISHINAZAKA, T.; MISHIMA, T.; TSUMAGAR, S.; YOKOTA, H. Three-dimensional reconstruction of the equine ovary. Anatomy Histology and Embryology, v. 34, p. 48-51, 2005.

LEITÃO, C.C.F; BRITO, I.; FROTA, I.M.A.; SILVA, J.R.V., Importance of local growth factors in the regulation of ovarian folliculogenesis in mammals. Acta Scientiae Veterinariae p. 215-224, 2009.

LINDEBERG, H.; KUNTSI, H.V.; KATILA, T. Predicting ovulation in the mare. International Congress on Animal Reproduction, v.4, p.144-146,1992. 
MARIANTE, A.S.; ALBUQUERQUE, M.S.M.; RAMOS, A.F. Revista Brasileira Reprodução Animal, Belo Horizonte, v.35, n.2, p.64 - 68,2011.

MCKINNON, A.O; VOSS J.L. Equine Reproduction. 5.ed, Ed. Lea \& Febiger, p.52, 1992.

SANTOS, S.A.; MCMANUS, C.; SILVA, J.S.; EGITO, A.; ABREU, U.G.P.; COMASTRI FILHO, J.A.; LARA, M.A.C. Estratégia de conservação in situ do cavalo Pantaneiro, 29p, 2003.

OLIVEIRA L.A; SOUZA J.A.T. Eficiência do hCG e LH na indução da ovulação e taxa de gestação em éguas da raça Quarto de Milha submetidas à cobertura única em tempo fixo. Revista Brasileira de Reprodução Animal, v.27, p.504-506, 2003.

ROBERTO DA COSTA, R.P.; BRANCO, V.; PESSA, P.; ROBALO SILVA, J.; FERREIRADIAS, G. Progesterone receptors and proliferating cell nuclear antigen expression in equine luteal tissue. Reproduction Fertility and Development, v. 17, p. 659-666, 2005.

SANTOS, S.A.; SERENO J.R.B.; Mazza, M.C.M.; Mazz, C.A. Origin of the Pantaneiro horse in Brazil. Arquivos brasileiros de zootecnia v. 4, p. 371 - 382, 1992.

SANTOS, S.A,; MAZZA, M.C.M.; SERENO, J.R.B.; ABREU, U.G.P.; SILVA, J.A. Avaliação e conservação do cavalo Pantaneiro, Circular técnica - EMBRAPA, v.21,1995

SANTOS, S.A.; CRISPIM, A.C.; SOARES, R.A.; PEREIRA, M.; SERENO, J.R.B. Hábitos de pastoreo de caballos pantaneiros. un elemento de adaptabilidad al pantanal brasileño. Arquivos brasileiros de zootecnia v.51, p.129-138, 2002.

VAN NIEKERK, C.H.; MORGENTHAL, J.C.; GERNEKE, W.H. Relationship between the morphology of and progesterone production by the corpus luteum in the mare. Journal of Reproduction and Fertility, v. 23, p.171-175, 1975.

\section{CAPÍTULO 2}




\title{
DINÂMICA FOLICULAR OVARIANA DE ÉGUAS DA RAÇA PANTANEIRO NAS DIFERENTES ESTAÇÕES DO ANO
}

\author{
Jessica Neri Nascimento ${ }^{\mathrm{a}}$, Alexandre Floriani Ramos ${ }^{\mathrm{b}}$, Rodrigo Arruda de Oliveira ${ }^{\mathrm{a}}$ \\ ${ }^{a}$ Programa de Pós-Graduação em Ciência Animal, Faculdade de Agronomia e \\ Medicina Veterinária, Universidade de Brasília, UnB, Brasília, Distrito Federal, Brasil; \\ ${ }^{\mathrm{b}}$ Embrapa Recursos Genéticos e Biotecnologia, Brasília, Distrito Federal, \\ Brasil;
}

RESUMO

Objetivou-se avaliar a dinâmica folicular e as características do ciclo estral de éguas da raça Pantaneiro. Os animais $(n=6)$ foram acompanhados diariamente durante um ciclo estral em cada uma das diferentes estações do ano, o tamanho dos folículos e do corpo lúteo (CL) foi registrado, assim como os dados de tonicidade e morfoecogenicidade uterina. . Houve diferença na duração do ciclo estral, para o Outono $(23,6 \pm 1,7$ dias) e o Inverno $(27,5 \pm 4,1$ dias) quando comparado com a Primavera (22,8 $\pm 1,6$ dias) e o Verão $(20,6 \pm 3,3$ dias). Para o dia da divergência e o tamanho folicular não houve diferença entre as estações. Também não houve diferença para o dia da dominância folicular e para o tamanho do folículo dominante. O tamanho médio do folículo pré ovulatório não diferiu entre as estações. A morfoecogenicidade uterina no momento pré ovulatório foi grau 2 nos meses de Outono, Inverno e Primavera e atingiu o grau máximo 3 (com pregas endometriais visíveis) no Verão. O maior tamanho do corpo lúteo foi visualizado no terceiro dia pós ovulação nos meses de Outono, Inverno e Verão e na Primavera o tamanho máximo do corpo lúteo foi apresentado no quarto dia pós ovulação. As éguas sofreram pouco efeito sazonal, já que a maioria dos animais estava cíclico durante as estações do ano; as éguas apresentaram a ocorrência de uma onda folicular maior e primária; os quesitos relacionados a duração do ciclo estral, dia da divergência e tamanho folicular, dia da dominância e folículo dominante, folículo pré ovulatório, morfoecogenicidade uterina, tamanho do corpo lúteo e tônus uterino são similares aos relatados por outras raças.

Palavras-chave: Ciclo estral; dinâmica folicular; égua Pantaneiro; sazonalidade

\section{OVARIAN FOLLICULAR DYNAMICS IN PANTANEIRO MARES \\ IN DIFFERENT SEASONS OF THE YEAR}




\begin{abstract}
Aimed to evaluate follicular dynamics and characteristics of the estrous cycle Pantaneiro breed mares. The animals $(n=6)$ were followed daily for a estrous cycle in each of the different seasons of the year, the size of the follicles and the corpus luteum (CL) was recorded as well as data and uterine tone morphoechogenicity. . There were differences on the estrous cycle, for autumn (23.6 \pm 1.7 days) and winter ( $27.5 \pm 4.1$ days) compared with the spring (22.8 \pm 1.6 days) and the summer (20.6 \pm 3.3 days). For the day of divergence and follicular size did not differ between seasons. There was no difference for the day of follicular dominance and the size of the dominant follicle. The average size of the pre ovulatory follicle did not differ between seasons. Uterine morphoechogenicity pre ovulatory time was grade 2 in the months of autumn, winter and spring and has reached the maximum grade 3 (with visible endometrial folds) in the summer. The larger size of the corpus luteum was visualized on the third day after ovulation during the months of autumn, winter and summer and spring the maximum size of the corpus luteum was made in the fourth post ovulation day. Mares have suffered little seasonal effect, since the majority of the animals was cyclical during the seasons; mares have submitted a a larger incidence of primary and follicular wave; the questions related to the estrous cycle, day of divergence and follicular size, day of dominance and dominant follicle, pre ovulatory follicle, uterine morphoechogenicity, body size luteum and uterine tone are similar to those reported in other races.
\end{abstract}

Keywords: estrous cycle; follicular dynamics; Pantaneiro mare; seasonality

\title{
1 INTRODUÇÃO
}


O reconhecimento do ciclo estral é um importante aliado nos programas de reprodução assistida, uma vez que a partir de sua manipulação podem ser realizados programas de inseminação artificial com sêmen congelado, sincronização de ovulação, coleta de ovócitos, transferência de embriões, seleção de receptoras.

Por serem poliéstricas estacionais de dias longos, durante os períodos transicionais (Outono e Primavera) e no período de contra estação (Inverno), as éguas tendem a ter uma fase anovulatória, chamada de anestro sazonal (Ginther, 1992).

A maneira mais comum de redução do período de anestro é por meio da iluminação artificial. Scraba e Ginther (1985) descrevem que éguas de pequeno porte, a exemplo das Pantaneiras, necessitam receber de 15 a 16 horas de iluminação por dia para que o período de anestro sazonal seja reduzido.

Outro fator que pode influenciar o ciclo estral é o volumoso ofertado para os animais. Carnevalle et al (1997) comparou três lotes com fornecimento de diferentes volumosos (pastagem seca, feno e pastagem verde) durante a transição vernal (Primavera) e seus resultados mostram que os animais alimentados com pastagem verde ovularam mais cedo do que os demais, o que reduziu o período de anestro.

Éguas de porte similar as da raça Pantaneiro, são descritas como possuindo uma onda folicular maior e primária e ciclo estral com duração de 24 dias (GINTHER et al,1993; Gastal et al, 1997).

Tendo em vista o crescimento da raça Pantaneiro e sua disseminação em todas as regiões do Brasil, a caracterização do seu ciclo estral irá auxiliar a diversos veterinários a estabelecerem seus protocolos de inseminações, superovulações e transferências de embrião. Desta forma, objetivou-se caracterizar a dinâmica folicular de éguas da raça Pantaneiro no Planalto Central.

\section{MATERIAIS E MÉTODOS}

\subsection{Local}

O Experimento foi realizado no Núcleo de Conservação de Recursos Genéticos Animais da Embrapa Recursos Genéticos e Biotecnologia, Fazenda Sucupira, Brasília - DF $\left(15^{\circ} 52^{\prime}-15^{\circ} 56^{\prime} \mathrm{S} 48^{\circ} 00^{\prime}-48^{\circ} 02^{\prime} \mathrm{O}\right)$ durante o ano de 2012. Com temperatura média durante o período do experimento de $20,3^{\circ} \mathrm{C}$, umidade relativa (UR) $73,6 \%$, e o índice de precipitação pluviométrica de 111,3 mm (RESUMO ANUAL - FAL, 2012) 
Todos os procedimentos foram aprovados pelo Comitê de Ética no Uso Animal (CEUA) do Instituto de Ciências Biológicas da Universidade de Brasília, sob o protocolo UnBDoc No $126531 / 2011$.

\subsection{Os animais}

Foram utilizadas 06 éguas da raça Pantaneiro, todas ginecologicamente sadias. Com idade variando de 5 a 16 anos, intervalo de peso de 300 a $380 \mathrm{~kg}$ e altura de cernelha entre 1,45 a 1,55 m; mantidas em pastagem com forrageiras do gênero Brachiara Brizantha e Panicum, com sal mineral e água ad libitum

\subsection{A avaliação}

Foi avaliado um ciclo estral de cada égua em cada uma das quatro estações do ano (Primavera, Verão, Outono, Inverno) no ano de 2012. Para que houvesse o mínimo de exposição do animal a nova estação, todos os trabalhos começaram na segunda semana após o equinócio ou solstício.

O início do ciclo foi marcado pelo dia da ovulação, denominado D0, o último dia do ciclo foi marcado por uma nova ovulação. Para pré-sincronização foi realizado cinco miligramas (mg) de Dinoprost Trometamina (Lutalyse®) em todos os animais e três dias após a aplicação começaram a ser monitorados por ultrassonografia para que fosse identificado o momento da ovulação (D0).

O monitoramento por palpação e ultrassonografia transretal foi diário (sonda linear, frequência de cinco mHZ, aparelho Mindray® DP-2200vet), sendo que não houve alteração de técnico durante o procedimento.

Durante palpação retal foi avaliado tônus uterino, na classificação de 01 a 04 , sendo 01 muito turgido (progesterônico) e 04 flácido (estrogênico) (FLEURY, et al, 2006). Visualmente, o escore de condição corporal (ECC) também foi avaliado de 01 a 09, com 01 pobre, 09 obeso e 05 moderado, representando o peso ideal da espécie (HENNEKE et al, 1983)

$\mathrm{Na}$ imagem de ultrassom foi descrito a morfoecogenicidade uterina de 0 (com linha de colabamento presente) a 03 (com visualização das pregas endometriais) (CUERVOARANGO et al, 2008). Os folículos e os corpos lúteos foram medidos em 04 pontos, formando ao centro a angulação de $90^{\circ}$, foi retirada média destas medidas para predizer o tamanho final. 
O dia da divergência folicular foi considerado aquele em que a taxa de crescimento de um ou dois folículos foi maior que a dos demais. O maior folículo neste instante foi mensurado e foi indicado como o tamanho folicular no momento da divergência.

O dia da dominância folicular é aquele em que um folículo passa a exercer efeito inibitório sobre os outros, fazendo com que estes entrem em atresia ou regressão.

As análises dos dados foram realizadas com o auxílio do software estatístico gratuito R Core Team 2013 (R: A language and environment for statistical computing. $R$ Foundation for Statistical Computing, Viena, Áustria) adotando-se como nível de significância $P \leq 0,05$. A comparação de médias das características foliculares e luteais nas estações do ano foram feitas com o teste de Kruskal - Wallis. Os dados foram apresentados como média \pm erro padrão da média (EPM). A taxa de crescimento foi estimada através do modelo Gompertz reparametrizado para dar sentido biológico (fol = A x expo (-B x exp (-C x dias)), em que A não tem sentido prático, B é a taxa de crescimento (mm) após o ponto de inflexão e $\mathrm{C}$ é a taxa de crescimento até o ponto de inflexão.

\section{RESULTADOS}

Foram acompanhados 24 ciclos estrais de éguas da raça Pantaneiro nas diferentes estações do ano. Na tabela 01 podem ser visualizados os parâmetros avaliados e as médias correspondentes a cada estação do ano.

Tabela 01. Características do ciclo estral de éguas Pantaneiro no Planalto Central nas diferentes estações do ano.

\begin{tabular}{|c|c|c|c|c|}
\hline Parâmetro & Outono & Inverno & Primavera & Verão \\
\hline Éguas Cíclicas & $06 / 06$ & $04 / 06$ & $05 / 06$ & $06 / 06$ \\
\hline $\begin{array}{lr}\text { Duração } & \text { do } \\
\text { ciclo } & \text { estral } \\
\text { (dias) } & \end{array}$ & $23,6 \pm 1,7^{\mathrm{a}}$ & $27,5 \pm 4,1^{\mathrm{a}}$ & $22,8 \pm 1,6^{\mathrm{ab}}$ & $20,6 \pm 3,3^{b}$ \\
\hline $\begin{array}{l}\text { Dia da } \\
\text { divergência } \\
\text { (dia) }\end{array}$ & $14,3 \pm 5,1$ & $15,5 \pm 2,3$ & $15,2 \pm 1,9$ & $13,1 \pm 2,1$ \\
\hline $\begin{array}{l}\text { Tamanho } \\
\text { folicular na } \\
\text { divergência } \\
(\mathbf{m m})\end{array}$ & $19,6 \pm 6,5$ & $17,2 \pm 3,7$ & $24 \pm 4,6$ & $19,3 \pm 2,5$ \\
\hline
\end{tabular}




\begin{tabular}{lllll}
\hline $\begin{array}{l}\text { Dia da } \\
\text { dominância } \\
\text { (dia) }\end{array}$ & $17,3 \pm 5,3$ & $18,2 \pm 3,2$ & $18,6 \pm 0,5$ & $15,8 \pm 2,6$ \\
\hline $\begin{array}{l}\text { Tamanho do } \\
\text { folículo } \\
\text { dominante } \\
\text { (mm) }\end{array}$ & $29 \pm 4,1$ & $26 \pm 6,05$ & $34,4 \pm 2,5$ & $26,3 \pm 6,2$ \\
\hline $\begin{array}{l}\text { Tamanho do } \\
\text { folículo pré } \\
\text { ovulatório } \\
\text { (mm) }\end{array}$ & $44,1 \pm 7,6$ & $48,7 \pm 9,7$ & $44,8 \pm 2,7$ & $42,5 \pm 9,1$ \\
\hline $\begin{array}{l}\text { Taxa } \\
\text { crescimento } \\
\text { folicular } \\
\text { (mm/dia) }\end{array}$ & 4,29 & 5,46 & & \\
\hline $\begin{array}{l}\text { Dias de estro } \\
\text { (dias) }\end{array}$ & $5,3 \pm 2,5^{\mathrm{a}}$ & $9,25 \pm 3,3^{\mathrm{b}}$ & $4,2 \pm 1,4^{\mathrm{a}}$ & $5,1 \pm 2,3^{\mathrm{a}}$ \\
\hline
\end{tabular}

Letras diferentes na mesma linha indica que houve diferença entre as médias $(\mathrm{P} \leq 0,05)$.

As figuras a seguir (03-06) apresentam as curvas de crescimento folicular dos animais, individualmente, em cada uma das estações do ano. O ponto médio de inflexão pode ser denominado como o dia da divergência ou desvio folicular. Neste ponto o eixo $\mathrm{X}$ indica o dia do ciclo estral e o eixo Y indica o tamanho do folículo na ocorrência do desvio. 


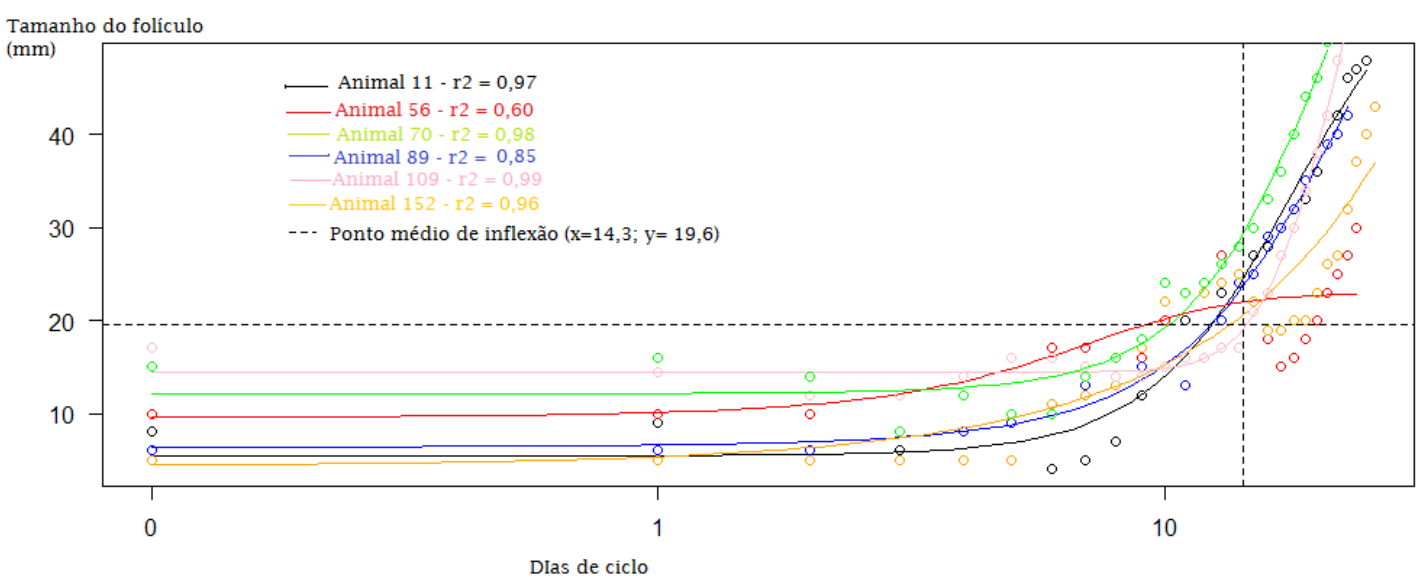

Figura 03. Curva de crescimento folicular de éguas Pantaneiras criadas no Planalto Central nos meses de Outono.

Neste caso, pode-se observar que o animal 56 (vermelho), se distanciou da curvatura padrão dos demais e gerou um baixo r2 $(0,60)$. É importante ressaltar que durante o período deste experimento esta égua foi lesionada o que pode ter interferido no padrão da curva folicular devido ao aumento de Prostaglandina endógena.

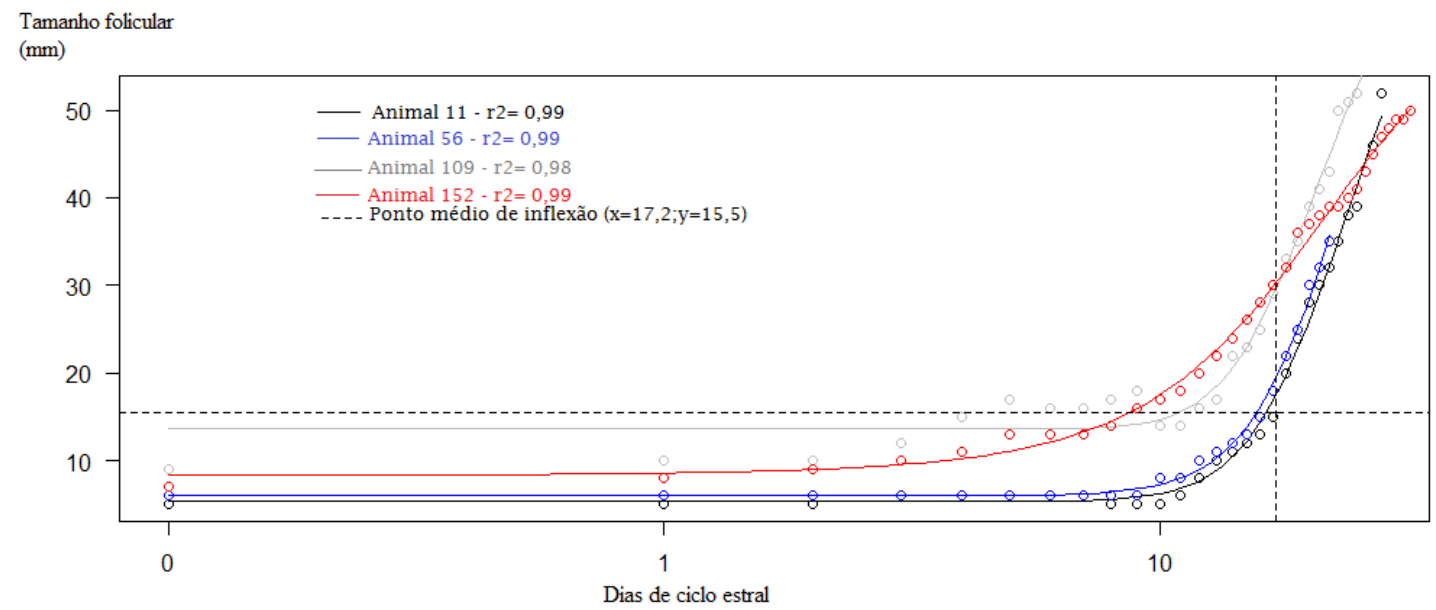

Figura 04. Curva de crescimento folicular de éguas Pantaneiras criadas no Planalto Central durante o Inverno.

No inverno a quantidade de animais cíclicos foi menor que nas demais estações do ano. 


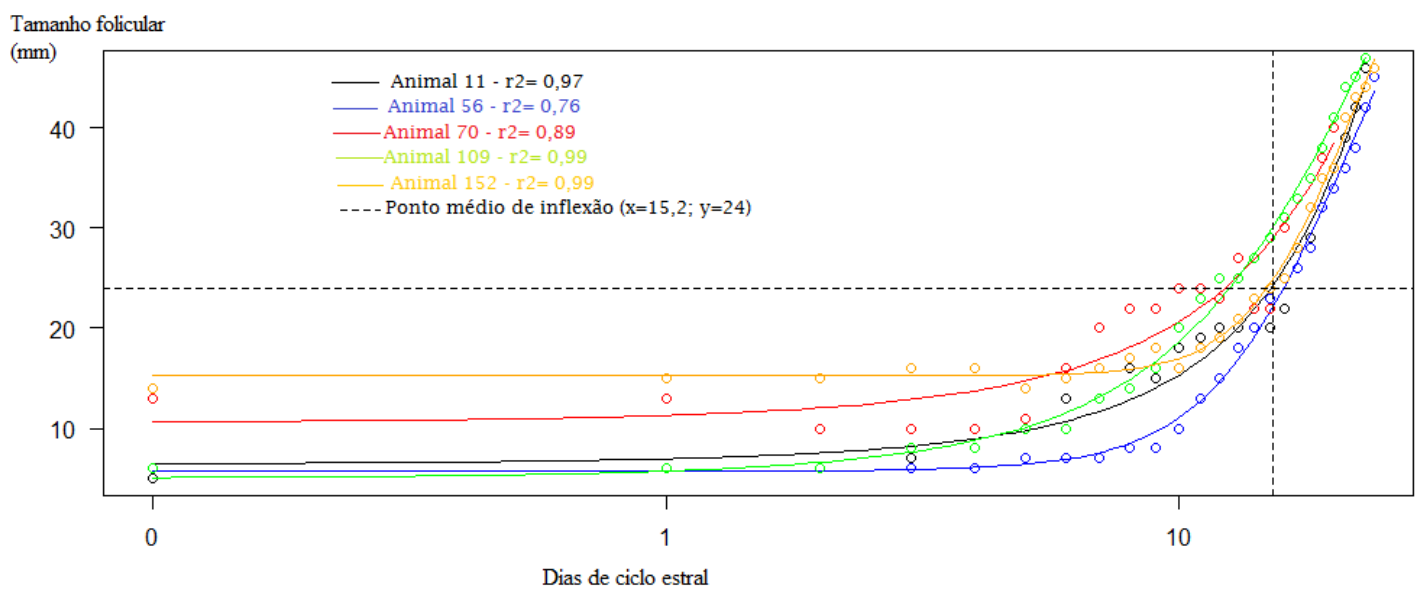

Figura 05. Curva de crescimento folicular de éguas Pantaneiro criadas no Planalto Central durante a Primavera.

Na Primavera apenas um animal (89) não apresentou ciclo estral normal, este mesmo animal não apresentou crescimento folicular relevante durante o Inverno.

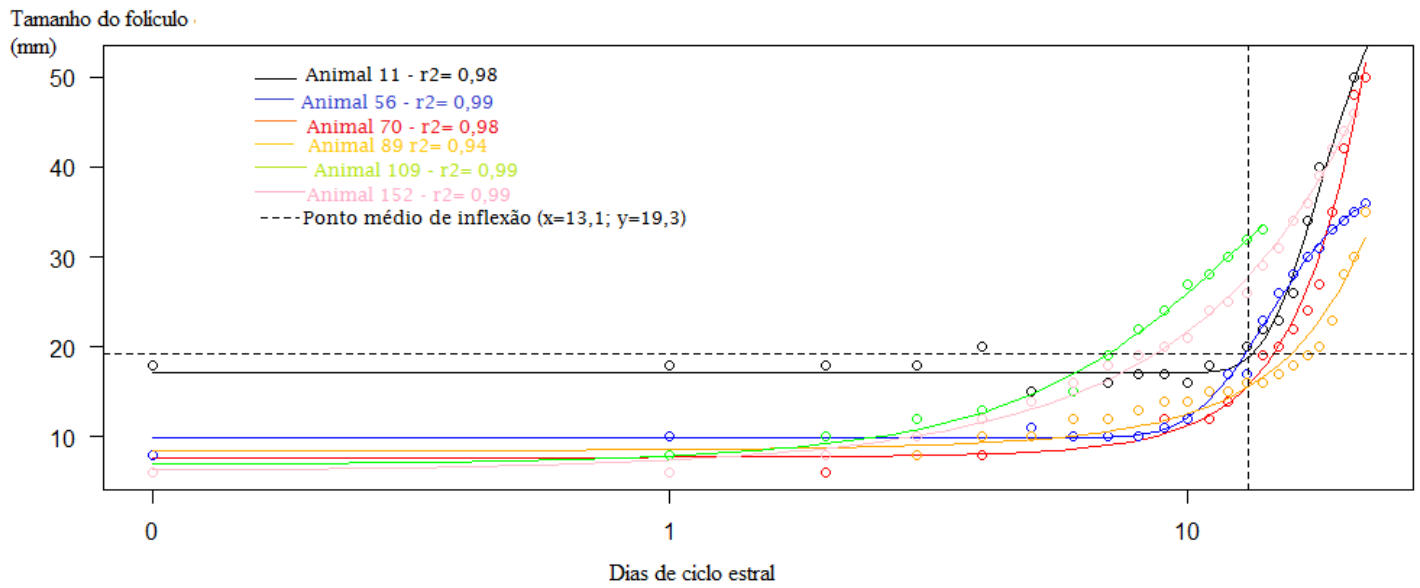

Figura 06. Curva de crescimento folicular de éguas Pantaneiro criadas no Planalto Central durante o Verão.

No Verão todas as éguas ciclaram normalmente.

As éguas apresentaram uma onda folicular maior e primária durante o ciclo estral. Houve a ocorrência de uma dupla ovulação no Outono.

O escore corporal variou entre 4 (moderadamente magro) e 5 (moderado). 
A figura 07 exemplifica o grau de edema considerado máximo (3) durante este

Estudo.

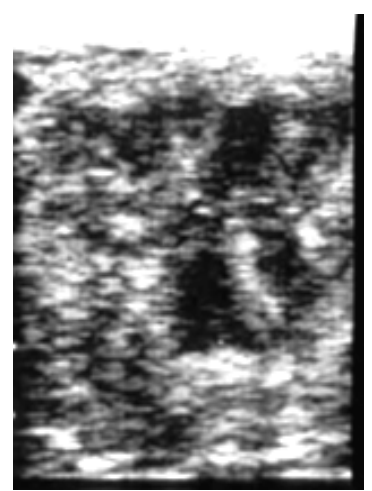

Figura 07. Edema uterino grau 3.

Fonte: Arquivo Pessoal

\section{DISCUSSÃO}

A duração do ciclo estral em éguas da raça Pantaneiro apresentou diferença entre as estações do ano. No Outono (23,6 $\pm 1,7$ dias) e no Inverno (27,5 \pm 4,1 dias) o ciclo estral foi mais prolongado que na Primavera (22,8 $\pm 1,6$ dias) e Verão (20,6 \pm 3,3 dias), $\mathrm{P}<0,05$. O aumento na duração do ciclo estral nos meses de Outono e Inverno pode ser explicado pela redução da incidência luminosa nestes meses, o que gera aumento da secreção de melatonina pela glândula Pineal, com a consequente redução nos níveis de GnRH, FSH, LH e a redução das funções reprodutivas.

No Planalto Central os dias longos possuem em torno de 13,9 horas de luz/dia e os dias curtos 11,9 horas luz/dia. Segundo Scraba e Ginther (1985) éguas de porte similar as Pantaneiras precisam em média de aproximadamente 15 horas de luminosidade para que ocorra a redução dos efeitos provocados pela baixa incidência de luz. Neste Experimento os animais eram mantidos a campo, sem qualquer interferência de luz artificial. A permanência da maioria das éguas em atividade reprodutiva mostra que estes animais precisam de uma menor quantidade de luz para se manter cíclicos nas condições deste trabalho.

Outros fatores estão associados ao aumento da duração do ciclo estral e ao prolongamento dos dias de estro. Pastagens secas ou sem manutenção adequada podem atrasar o momento da ovulação e prolongar os dias de ciclo estral (Carnevale et al, 1997). Animais com peso abaixo do esperado e pouco percentual de gordura demoram mais para apresentarem a primeira ovulação após o solstício de Inverno (Gentry et. al, 1997). Neste 
estudo, as éguas não sofreram com redução da ECC, no entanto, as pastagens estavam severamente degradadas devido a um extenso período de seca, o que pode ter prolongado a duração do ciclo estral e os dias de estro nos meses de Inverno.

A idade é outro fator que pode influenciar no ciclo estral, sendo que éguas mais novas ( 3 - 7 anos) possuem mais atividade folicular que as velhas ( $\geq 14$ anos) (Carnevale $e t$ $a l, 1997)$. Neste estudo com éguas Pantaneiro, acredita-se que a idade avançada influenciou na atividade reprodutiva de um animal (égua 89), sendo que este não mostrou atividade reprodutiva nos meses de Inverno e Outono.

No entanto, mesmo com a redução da produção hormonal no Inverno, devido a menor incidência de luminosidade e associado a redução de forragem. A maioria dos animais se manteve cíclicos, sendo que nestes meses houve a menor quantidade de éguas em plena atividade reprodutiva $(\mathrm{n}=4)$.

O dia e tamanho do folículo dominante corroboram com os descritos por Pierson que cita que folículos com mais de $25 \mathrm{~mm}$ de diâmetro já são considerados dominantes e possuem quantidade de estradiol $17 \beta$ maior que as demais estruturas foliculares.

A partir do dia da dominância folicular a morfoecogenicidade uterina vai se modificando, gerando uma estrutura heterogênea com a possibilidade de visualização das pregas endometriais. $\mathrm{O}$ edema uterino é provocado pelo aumento do estradiol intrafolicular e chega ao seu grau máximo juntamente com o surgimento do folículo pré ovulatório (GASTAL e GINTHER, 2006). As éguas Pantaneiras apresentaram maior grau de morfoecogenicidade (3) durante o Verão.

O tamanho do folículo pré ovulatório encontrado nas éguas Pantaneiras foi maior (42,5 \pm 9,1 mm no Verão) do que o descrito por Ginther et al (2001) que cita o folículo pré ovulatório $\geq 35 \mathrm{~mm}$ para éguas de porte similar as da raça Pantaneiro. Valle et al (2005) avaliaram o ciclo estral de éguas mestiças de Mangalarga Marchador e relata folículos pré ovulatórios de aproximadamente $38 \mathrm{~mm}$. Para Davies Morel et al (2010) o tamanho do folículo ovulatório está relacionado com o sucesso e eficácia na vida reprodutiva, e afirma que éguas mais velhas tendem a possuir um menor diâmetro de folículo pré ovulatório. Neste Experimento, as éguas mais velhas apresentaram diâmetro de folículo pré ovulatório dentro da média das éguas mais novas.

A taxa de crescimento folicular para as éguas da raça Pantaneira neste Estudo foi bem elevada e não foram encontrados valores similares na literatura. Não foram encontradas justificativas biológicas para este acontecimento. No entanto, o delineamento das 
curvas de crescimento folicular apresentado pelas éguas Pantaneiro está dentro do padrão apresentado por outras raças.

A duração da fase estral foi maior nos meses de Inverno, e também é justificável pela sazonalidade e condição da forrageira oferecida.

A estrutura lútea apresentou seu maior volume $(45 \mathrm{~mm})$ no terceiro dia pósovulação durante o Verão, com tônus uterino turgido (grau 2). O aumento do tônus uterino entre os dias 0 e 6 pós ovulação foi encontrado também por Bonafos et al (1994) em éguas prenhas e não prenhas. O volume máximo da estrutura é identificada somente ao terceiro dia quando as células luteais já estão formadas (AURICH, 2011) e criam uma imagem homogênea e bem delimitada. Do quarto dia em diante após a ovulação a estrutura já passa a ser encoberta por parênquima e há uma tendência a desorganização da estrutura. 


\section{CONCLUSÃO}

As éguas Pantaneiras possuem características do ciclo estral muito próxima a 'éguas pôneis' (ex.: duração do ciclo estral, no entanto, deve ser tratada como uma raça única de identidade própria. Este fato reforça a necessidade de caracterização de dados reprodutivos da raça.

As éguas Pantaneiro no Planalto Central aparentam sofrer pouco efeito da sazonalidade. 


\section{REFERÊNCIAS BIBLIOGRÁFICAS}

AURICH, C. Reprodutive cycle of horses. Animal Reproduction Science, v.124, p.220-228, 2011.

BONAFOS, L.D.; CARNEVALE, E.M.; SMITH, C.A.; GINTHER, O.J. Development of uterine tone in nonbred and pregnant mares . Theriogenology, v.42, p. 1247-1255,1994.

CARNEVALE, E.M.; HERMENEL, M.J; T, GINTHER O.J. Age and pasture effects on vernal transition in mares. Theriogenology, v 47 pg.1004-1018, 1997

CUERVO-ARANGO, J.; NEWCOMBE, J. R. Repeatability of preovulatory follicular diameter and uterine edema pattern in two consecutive cycles in the mare and how they are influenced by ovulation inductors. Theriogenology, v. 69, p.681-687, 2008.

DAVIES MORELA, M.C.G.; NEWCOMBEB, J.R.; HAYWARDA, K. Factors affecting preovulatory follicle diameter in the mare: the effect of mare age, season and presence of other ovulatory follicles (multiple ovulation). Theriogenology, v.74, p.1241-1247, 2010.

FARIAS, N.D.; SILVA, C.M. Revista Centro de Ciências Rurais, v.15, p.163 - 168, 1985.

FAZENDA ÁGUA LIMPA - UnB. Resumo Anual de Dados Agrometereolóicos, 2012.

GASTAL E.L; GASTAL M.O; GINTHER O.J. Experimental assumption of dominance by smaller follicle ans associated hormonal changes in mares. Biology of reproduction, v. 61 p. 724- 730, 1999.

GASTAL, E. L.; GASTAl, M. O.; GINTHER, O. J. Serrated granulosa and other discrete ultrasound indicators of impending ovulation in mares. Journal of Equine Veterinary Science, v.26, 2006.

GASTAL, E.L.; GASTAL, M.O.; BERGFELT, D.R.; GINTHER, O.J. Role of diameter differences among follicles in selection of future dominant follicle in mares. Biology and Reproduction, v57, pg.132-1327, 1997. 
GENTRY，L.R.; THOMPSON，D.L.; GENTRY，G.T.; DAVIS，K.A.; GODKE，R.A.; CARTMILL, J,Á. The relationship between body condition, leptin, and reproductive and hormonal characteristics of mares during the seasonal anovulatory period. Journal of Animal Science, v.80, p.2695-2703,2002.

GINTHER O. J. Reproductive biology of the mares basic and apllied aspects, 2 edição, ed. Equiservices, p. 176 - 185, 1992.

GINTHER OJ. Selection of the dominant follicle in cattle and horses. Animal Reproduction Science, v.60, p.61-79, 2000.

GINTHER, O.J; BERGFELT ,D.R. Growth of small follicles and concentrations of FSH during the equine estrous cycle. Journal of Reproduction and Fertility, v.99, pg.99-105, 1993.

GINTHER, O.J.; GASTAL, E.L.; GASTAL, M.O.; BEG, M.A. Dynamics of the equine preovulatory follicle and periovulatory hormones: what's new? Journal of Equine Veterinary Science, v. 28, p. 454-460, 2008.

HEIDLER, B.; AURICH, J.E.; POHL, W.; AURICH, C. Body weight of mares and foals, estrous cycles and plasma glucose concentration in lactating and non-lactating Lipizzaner mares. Theriogenology v. 61, p. 883-893, 2004.

HENNEKE, D. R.; POTTER, G. D.; KREIDER, J. L.; YEATES, B. F. Relationship between condition score, physical measurments and body fat percentage in mares. Equine Veterinary Journal, v.15, p. 371 - 372, 1983.

KOSKINEN, E.; KUNTSI, H.; LINDEBERG, H.; KATILA, T. Predicting ovulation in the mare on the basis of follicular growth and serum oestrone sulphate and progesterone levels. Journal of Veterinary Medicine, v.36 p. 229-304, 1989.

MELO, M.I.V.; SERENO, J.R.B.; HENRY, M.; CASSALI, G. D. Peripuberal sexual development of Pantaneiro stallions. Theriogenology,v.50, p. 727-737, 1998. 
MISERANI, M.G; MCMANUS, C; SANTOS, S.A; SILVA, J.A; MARIANTE, A.S; ABREU, U.G.P. Avaliação dos Fatores que Influem nas Medidas Lineares do Cavalo Pantaneiro. Revista Brasileira de Zootecnia, v.31, 2002.

PIERSON, R. A. Foliculogenesis and ovulation. In: MCKINNON, A. O.; VOSS, J. L. Equine reproduction. Malvern: Lea \& Febiger, p. 161-171,1993.

SANTOS, S.A; CRISPIM, S.M.A.; SOARES, A.C.; MAURO, R.A.; PEREIRA, M.; SERENO, J.R.B. Hábitos de pastoreo de caballos pantaneiros. Un elemento de adaptabilidad al pantanal brasileño. Archivos de zootecnia, v. 51, p. 133, 2002.

SCRABA, S. T.; O. J. GINTHER. Effects of lighting program s on onset of the ovulatory season in mares. Theriogenology,v.24,1985.

SERENO, J.R.B; ZÚCCARI, C.E.S.N; SANTOS, S.A; MAZZA, M.C.M. Avaliação do desempenho reprodutivo e estabelecimento da estação de monta de eqüinos em regime de monta natural a campo no pantanal. Embrapa - Comunicado técnico, nº 15, 1996.

STABENFELDT GH; HUGHES JP; EVANS JW; GESCHWIND II. Unique aspects of the reproductive cycle of the mare. Journal of Reproduction and Fertility, v.23, p. 155-160, 1975.

VALLE, G.R.; SILVA FILHO, J.M.; PALHARES, M.S. Características cíclicas e ovulatórias de éguas mestiças em Minas Gerais, Brasil. Arquivo de ciências veterinárias e zoologia, UNIPAR, v.8, p. 155-163,2005.

WILL, K.; KIHN, W.; LEIDL, W. Sonographic studies of the preovulatory follicles for predicting the time of ovulation in mares. Dtsch. Tierarztl. Wochenschr, v. 95, p. 362-365, 1988.

ZÚCCARI, C.E.S.N.; NUNES, D.B.; CORRÊA FILHO, R.A.C. Eficiência reprodutiva de éguas da raça pantaneira durante as estações de monta 1995/2000. Arquivos Brasileiros de Zootecnia, v.51, p. 139-148, 2002. 
ZÚCCARI, C.E.S.N.; NUNES, D.B; DE PAULA, F.A.L; FERREIRA, C.S; COSTA E SILVA, E.V. Recongelação do sêmen de garanhões pantaneiros. IV Simpósio sobre recursos nacionais e sócio- econômicos do Pantanal, Corumbá/MS, 2004. 


\title{
CAPÍTULO 3 \\ DINÂMICA FOLICULAR OVARIANA DE ÉGUAS DA RAÇA CAMPEIRA NAS DIFERENTES ESTAÇÕES DO ANO
}

\author{
Jessica Neri Nascimento $^{\mathrm{a}}$, Alexandre Floriani Ramos; Rodrigo Arruda de Oliveira ${ }^{\mathrm{a}}$ \\ ${ }^{\text {a} P r o g r a m a ~ d e ~ P o ́ s-G r a d u a c ̧ a ̃ o ~ e m ~ C i e ̂ n c i a ~ A n i m a l, ~ F a c u l d a d e ~ d e ~ A g r o n o m i a ~ e ~}$ \\ Medicina Veterinária, Universidade de Brasília, UnB, Brasília, Distrito Federal, Brasil; \\ ${ }^{\mathrm{b}}$ Embrapa Recursos Genéticos e Biotecnologia, Brasília, Distrito Federal, \\ Brasil;
}

\begin{abstract}
RESUMO
Objetivou-se avaliar a dinâmica folicular e as características do ciclo estral de éguas da raça Campeiro, criadas no Planalto Central. Foram acompanhados seis animais diariamente durante um ciclo estral em cada uma das estações do ano, o tamanho dos folículos e do corpo lúteo (CL) foi registrado, assim como os dados de tonicidade uterina e morfoecogenicidade uterina. Houve diferença na duração do ciclo estral, entre a Primavera (23,6 $\pm 1,5$ dias) e o Inverno (23,7 $\pm 2,2$ dias) quando comparado com o Outono (20,3 $\pm 1,5$ dias) e o Verão (19,4 $\pm 2,7$ dias). Para o dia da divergência folicular o Outono (12,16 $\pm 2,5$ dias) e o Verão $(19,4 \pm$ 2,7 dias) diferiram do resultado encontrado no Inverno (15,5 $\pm 1,2$ dias) e Primavera (16,8 \pm 1,1dias). O tamanho folicular no dia da divergência não diferiu entre as estações do ano. $\mathrm{O}$ dia da dominância folicular foi o mesmo no Outono (17,2 $\pm 2,9$ dias) e Inverno (15,1 $\pm 2,4$ dias) e no Outono e Verão (13,8 $\pm 2,9$ dias). O Inverno e o Verão foram diferentes entre si, assim como o Inverno e Primavera ( $20 \pm 0,7$ dias). Para o tamanho do folículo dominante não houve diferença entre o Verão $(24 \pm 3,7 \mathrm{~mm})$ e o Outono ( $22,1 \pm 2,6 \mathrm{~mm})$. O tamanho folicular no Inverno $(24,2 \pm 3,2 \mathrm{~mm})$ foi o mesmo que os meses de Outono e Verão. O tamanho pré ovulatório não diferiu entre as estações. A morfoecogenicidade uterina no momento pré ovulatório foi de grau 3 (com pregas endometriais visíveis) em todas as estações. As éguas sofreram pouco efeito sazonal, já que a maioria dos animais estavam cícilicos durante as estações do ano. As éguas apresentaram a ocorrência de uma onde folicular maior e primária. Os quesitos relacionados a duração do ciclo estral, dia da divergência e tamanho folicular, dia da dominância e folículo dominante, folículo pré ovulatório, morfoecogenicidade uterina, tamanho do CL e tônus uterino são similares aos relatados por outras raças.

Palavras - chave: Ciclo estral; éguas; estações do ano; raça Campeiro.
\end{abstract}




\title{
OVARIAN FOLLICULAR DYNAMICS IN CAMPEIRO MARES IN DIFFERENT SEASONS
}

\begin{abstract}
Aimed to evaluate follicular dynamics and characteristics of the estrous cycle of Campeiro mares created in the Central Plateau. Six animals were observed daily for one estrous cycle in each of the seasons, the size of the follicles and the corpus luteum (CL) was recorded, and the data of uterine tone and uterine morphoechogenicity. There were differences on the estrous cycle, from spring (23.6 \pm 1.5 days) and winter $(23.7 \pm 2.2$ days $)$ compared with the autumn $(20.3 \pm 1.5$ days $)$ and the summer $(19.4 \pm 2.7$ days $)$. The day of follicle deviation autumn (12.16 \pm 2.5 days) and summer $(19.4 \pm 2.7$ days $)$ differed from the results found in winter $(15.5 \pm 1.2$ days $)$ and spring (16.8 \pm 1 ,1dias). Follicular size on the day of departure did not differ between the seasons. The day of follicular dominance was the same in autumn (17.2 \pm 2.9 days $)$ and winter $(15.1 \pm 2.4$ days $)$ and autumn and summer (13.8 \pm 2.9 days $)$. The winter and summer were different from each other, as well as winter and spring ( $20 \pm 0.7$ days). For the size of the dominant follicle was no difference between the summer $(24 \pm 3.7 \mathrm{~mm})$ and autumn $(22.1 \pm 2.6 \mathrm{~mm})$. Follicular size in winter $(24.2 \pm 3.2 \mathrm{~mm})$ was the same as the months of autumn and summer. The pre ovulatory size did not differ between seasons. Uterine morphoechogenicity in the pre ovulatory were grade 3 (endometrial with visible fold) in all seasons. Mares have suffered little seasonal effect, since the majority of the animals were cyclic during the seasons. The mares have submitted the occurrence of a primary and follicular largest wave. The items related to the estrous cycle, day of divergence and follicular size, day of dominance and dominant follicle, pre ovulatory follicle, uterine morphoechogenicity, CL size and uterine tone are similar to those reported in other races.
\end{abstract}

Key - words: estrous cycle; mares; seasons; Campeiro breed. 


\section{INTRODUÇÃO}

McManus et al (2005), caracterizaram a morfologia dos cavalos Campeiros e afirmaram que a pelagem predominante é castanha (40\%), seguida da baia (26\%) e tordilha (16\%), é um cavalo de porte pequeno com uma menor parcela de cavalos de porte médio. A altura de cernelha varia de 1,42 a 1,54 para machos e 1,40 a 1,50 para fêmeas, a cernelha tem altura geralmente inferior a da garupa, o que auxilia trabalho de tração .

Com seu efetivo ainda em redução, a preocupação em torno da conservação dos recursos genéticos desta espécie é crescente e com ela a necessidade de coletar dados referentes a estes animais é cada vez maior.

Objetivou-se com esse estudo fazer um levantamento de dados referente a duração do ciclo estral, dia da divergência e tamanho do folículo, dia da dominância e tamanho do folículo dominante, folículo pré ovulatório e comportamento uterino neste momento, tamanho máximo do corpo lúteo e tônus uterino.

\section{MATERIAIS E MÉTODOS}

\subsection{Local}

O experimento foi realizado no Núcleo de Conservação de Recursos Genéticos Animais da Embrapa Recursos Genéticos e Biotecnologia, Fazenda Sucupira, Brasília - DF $\left(15^{\circ} 52^{\prime}-15^{\circ} 56^{\prime} \mathrm{S} 48^{\circ} 00^{\prime}-48^{\circ} 02^{\prime} \mathrm{O}\right)$ durante o ano de 2012 . A temperatura $\left(\mathrm{T}^{\circ}\right)$ média durante a realização do experimento foi de $20,3^{\circ}$, umidade relativa (UR) $73,6 \%$, e o índice de precipitação pluviométrica de $111,3 \mathrm{~mm}$. (FAL,2012)

Todos os procedimentos foram aprovados pelo Comitê de Ética no Uso Animal (CEUA) do Instituto de Ciências Biológicas da Universidade de Brasília, sob o protocolo UnBDoc Nº126531/2011.

\subsection{Os animais}

Foram utilizadas seis éguas da raça Campeiro com idade variando de 8 a 14 anos, altura entre 1,50 e 1,55 m e intervalo de peso de 300 a $350 \mathrm{~kg}$, mantidas em pastagem com forrageiras do gênero Brachiara Brizanta e Panicum, suplementação com sal mineral e água ad libitum

\subsection{A avaliação}

Foi avaliado um ciclo estral de cada égua em cada uma das quatro estações do ano (Primavera, Verão, Outono, Inverno) no ano de 2012. Para que houvesse o mínimo de 
exposição do animal a nova estação, todos os trabalhos começaram na segunda semana após o equinócio ou solstício.

O início do ciclo foi marcado pelo dia da ovulação, denominado D0, o último dia do ciclo foi marcado por uma nova ovulação. Para pré-sincronização foi utilizado cinco miligramas (mg) de Dinoprost Trometamina (Lutalyse®) em todos os animais e três dias após a aplicação começaram a ser monitorados por ultrassonografia para que fosse identificado o momento da ovulação (D0).

O monitoramento por palpação e ultrassonografia transretal foi diário (sonda linear, frequência de cinco mHZ, aparelho Mindray® DP-2200vet), não houve alteração de técnico durante o procedimento.

Durante palpação retal foi avaliado tônus uterino, na classificação de 01 a 04, sendo 01 turgido (progesterônico) e 04 flácido (estrogênico) (FLEURY, et al, 2006). Visualmente, o escore de condição corporal (ECC) também foi avaliado de 01 a 09 , com 01 pobre, 09 obeso e 05 moderado, representando o peso ideal da espécie (HENNEKE et al, 1983)

$\mathrm{Na}$ imagem de ultrassom foi descrito o edema uterino de 0 (com linha de colabamento presente) a 03 (visualização clara das pregas endometriais) (CUERVOARANGO et al, 2008). Os folículos e os corpos lúteos foram medidos em 04 pontos, formando ao centro a angulação de $90^{\circ}$, foi retirada média destas medidas para predizer o tamanho final.

As análises dos dados foram realizadas com o auxílio do software estatístico gratuito R Core Team 2013 (R: A language and environment for statistical computing. $R$ Foundation for Statistical Computing, Viena, Austria) adotando-se como nível de significância $P \leq 0,05$. A comparação de médias das características foliculares e luteais nas estações do ano foram feitas com o teste de Kruskal - Wallis. Os dados foram apresentados como média \pm erro padrão da média (EPM). A taxa de crescimento foi estimada através do modelo Gompertz reparametrizado para dar sentido biológico (fol $=\mathrm{A} \times \operatorname{expo}(-\mathrm{B} \times \exp (-\mathrm{C} \times$ dias)), em que A não tem sentido prático, B é a taxa de crescimento (mm) após o ponto de inflexão e C é a taxa de crescimento inicial, até o ponto de inflexão. 


\section{RESULTADOS}

A tabela 02 aborda os parâmetros avaliados e os resultados obtidos separadamente em cada uma das estações do ano.

Tabela 02. Caracaterísticas do ciclo estral de éguas da raça Campeiro criadas no Planalto Central nas diferentes estações do ano de 2012.

\begin{tabular}{|c|c|c|c|c|}
\hline Parâmetro & Outono & Inverno & Primavera & Verão \\
\hline Éguas Cíclicas & $06 / 06$ & $04 / 06$ & $05 / 06$ & $05 / 06$ \\
\hline $\begin{array}{lr}\text { Duração } & \text { do } \\
\text { ciclo } & \text { estral } \\
\text { (dias) } & \end{array}$ & $20,3 \pm 1,7^{b}$ & $23,7 \pm 2,2^{\mathrm{a}}$ & $23,6 \pm 1,5^{\mathrm{a}}$ & $19,4 \pm 2,7^{b}$ \\
\hline $\begin{array}{l}\text { Dia da } \\
\text { divergência } \\
\text { (dia) }\end{array}$ & $12,16 \pm 2,5^{b}$ & $15,5 \pm 1,2^{a}$ & $16,8 \pm 1,1^{\mathrm{a}}$ & $11,8 \pm 4,1^{b}$ \\
\hline $\begin{array}{l}\text { Tamanho } \\
\text { folicular na } \\
\text { divergência } \\
(\mathbf{m m})\end{array}$ & $17,6 \pm 2,1$ & $18,5 \pm 1,9$ & $20,4 \pm 3,2$ & $19 \pm 6,4$ \\
\hline $\begin{array}{l}\text { Dia da } \\
\text { dominância } \\
\text { (dia) }\end{array}$ & $17,2 \pm 0,5^{b c}$ & $15,1 \pm 2,4^{b}$ & $20 \pm 0,7^{\mathrm{a}}$ & $13,8 \pm 2,9^{c}$ \\
\hline $\begin{array}{l}\text { Tamanho do } \\
\text { folículo } \\
\text { dominante } \\
(\mathbf{m m})\end{array}$ & $22,1 \pm 2,6^{b}$ & $24,2 \pm 3,2^{\mathrm{ab}}$ & $31,2 \pm 6,9^{\mathrm{a}}$ & $24 \pm 3,7^{b}$ \\
\hline $\begin{array}{l}\text { Tamanho do } \\
\text { folículo pré } \\
\text { ovulatório } \\
(\mathbf{m m})\end{array}$ & $22,1 \pm 2,6$ & $24,2 \pm 3,2$ & $31,2 \pm 6,9$ & $24 \pm 3,7$ \\
\hline $\begin{array}{l}\text { Taxa de } \\
\text { crescimento } \\
\text { folicular } \\
\text { (mm/dia) }\end{array}$ & 6,42 & 6,89 & 6,57 & 4,62 \\
\hline $\begin{array}{l}\text { Dias de estro } \\
\text { (dias) }\end{array}$ & $6,16 \pm 1,1$ & $7,5 \pm 2,3$ & $4,6 \pm 2,0$ & $6,6 \pm 0,5$ \\
\hline
\end{tabular}

Letras iguas na mesma linha representam que não houve diferença entre as médias $(\mathrm{P} \geq 0,05)$

As figuras a seguir (7-10) representam as curvas de crescimento folicular de cada um dos animais observados nas diferentes estações do ano. O ponto de inflexão também 
pode ser denominado como ponto de divergência ou desvio folicular. $\mathrm{O}$ eixo $\mathrm{X}$ representa o dia do ciclo e o eixo Y representa o tamanho folicular no dia deste acontecimento.

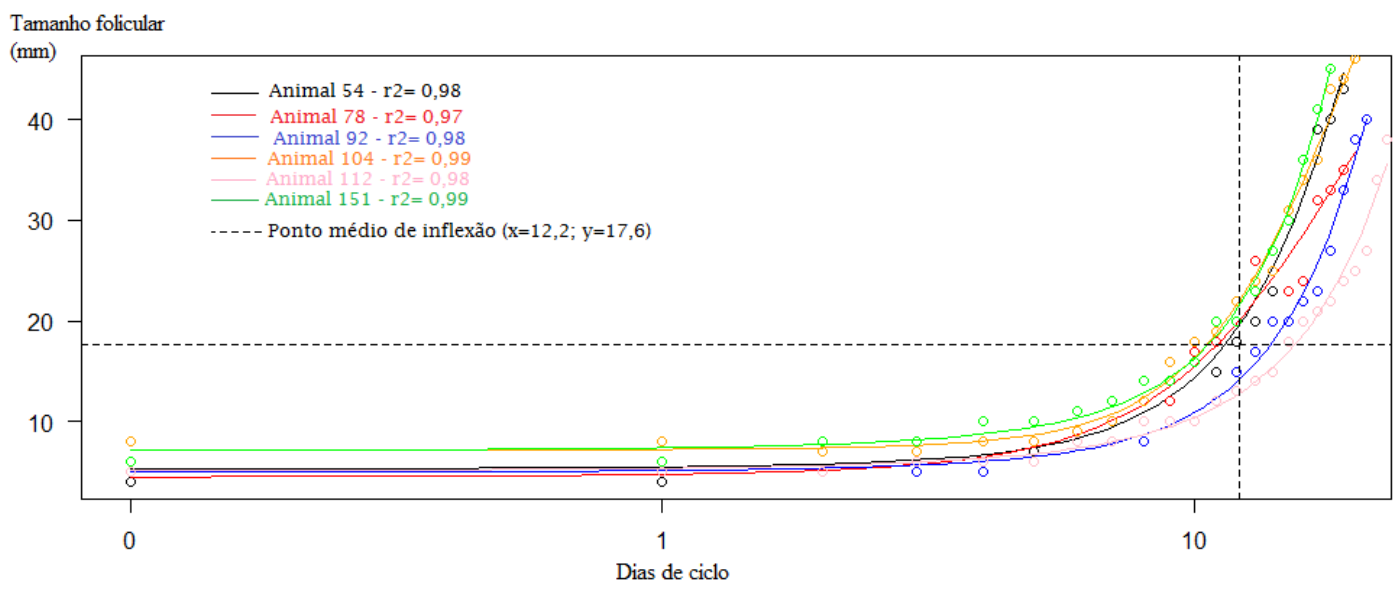

Figura 08. Curva de crescimento folicular de éguas Campeiro criadas no Planalto Central nos meses de Outono.

Todos os animais evoluíram normalmente durante esta estação.

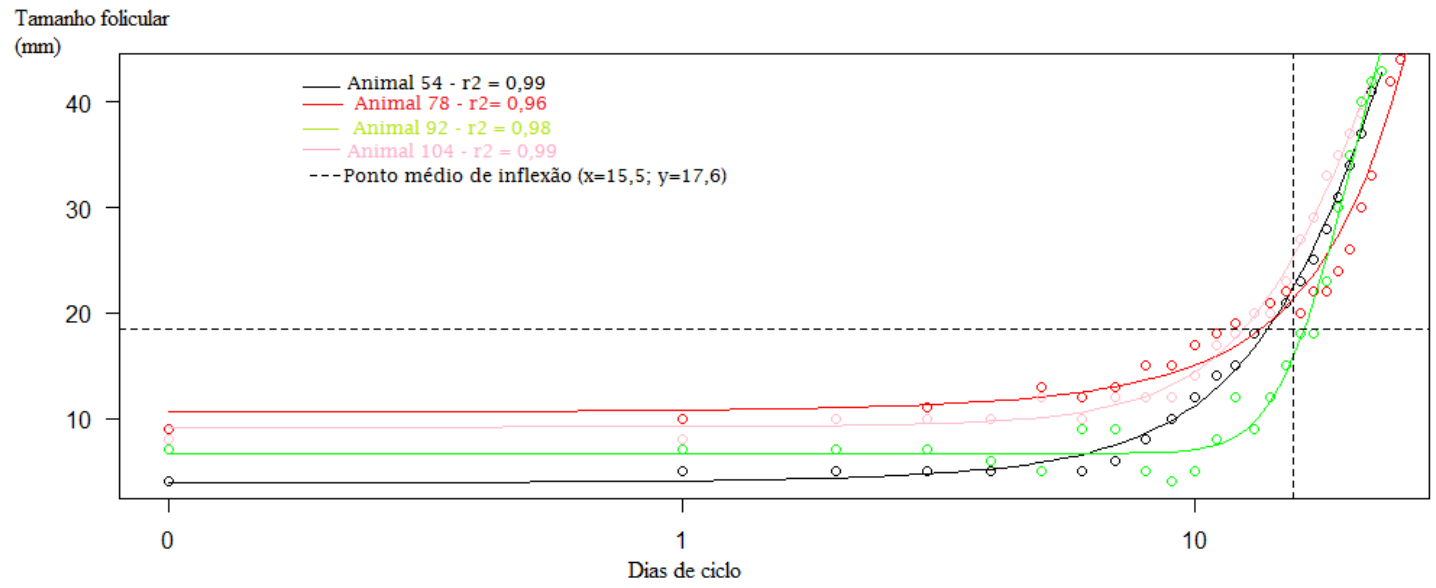

Figura 09. Curva de crescimento folicular de éguas Campeiro criadas no Planalto Central nos meses de Inverno.

Apenas quatro dos seis animais estudados tiveram crescimento folicular relevante para o estudo. 


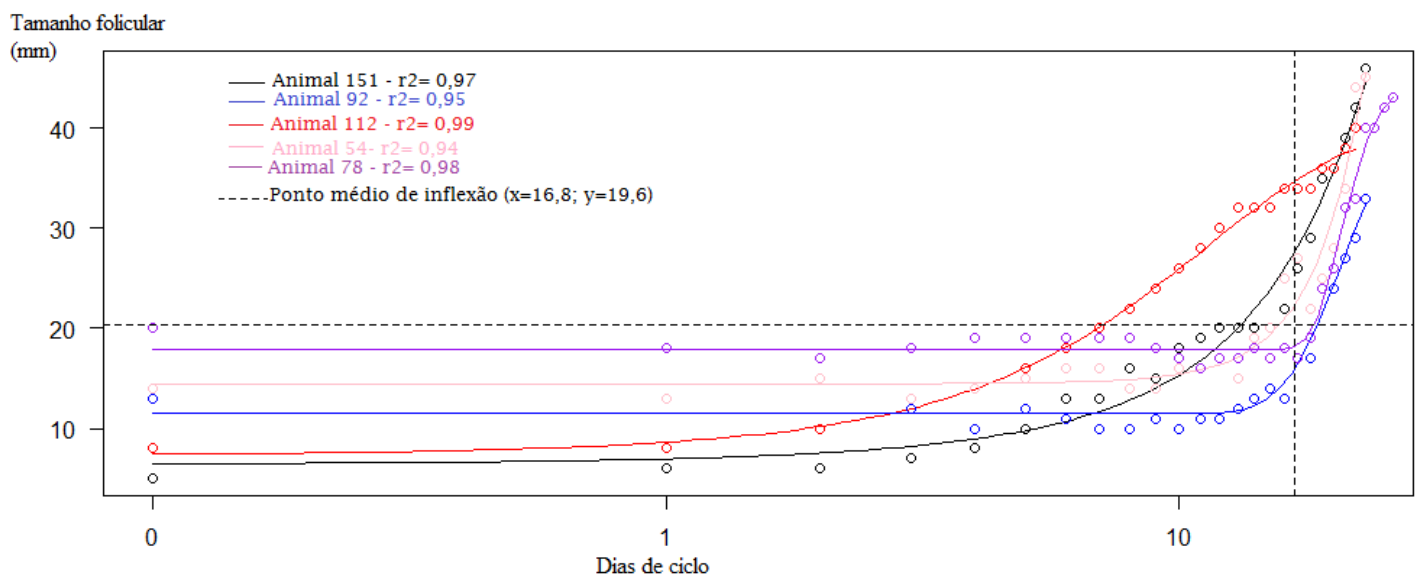

Figura 10. Curva de crescimento folicular de éguas da raça Campeiro criadas no Planalto Central durante a Primavera.

Nesta fase de transição vernal, cinco dos seis animais estudados voltaram a completar seu ciclo estral normalmente. O animal 104, não completou seu ciclo estral.

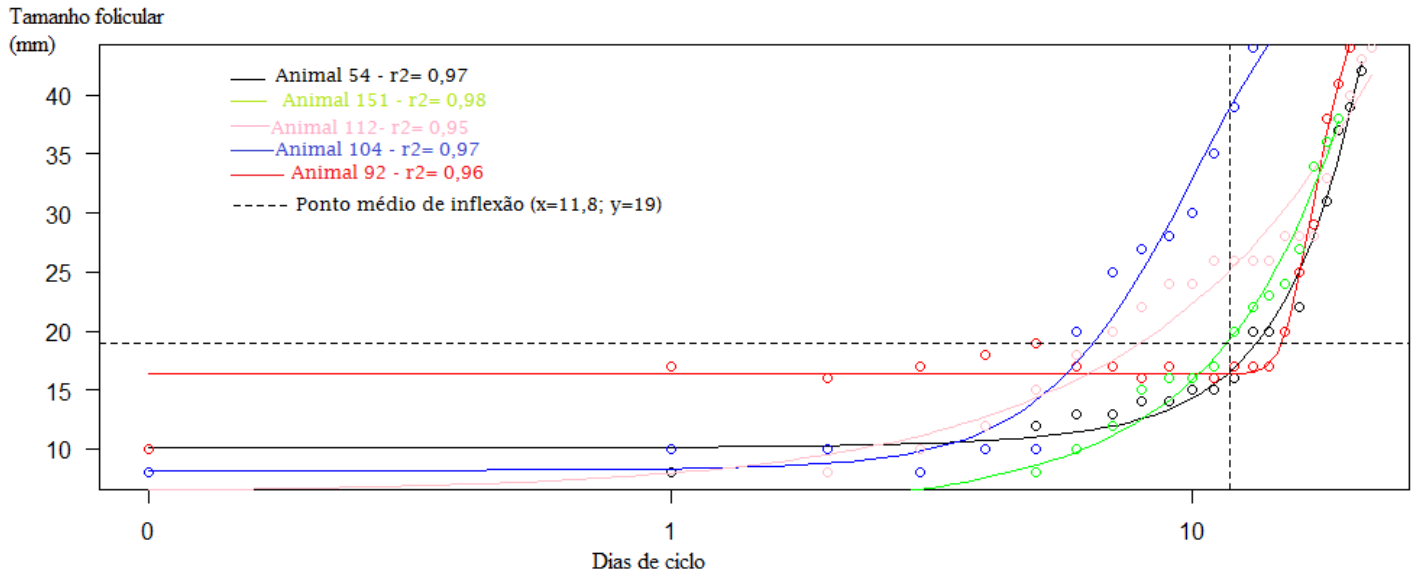

Figura 11. Curva de crescimento folicular de éguas da raça Campeiro criadas no Planalto Central durante o Verão.

Novamente, apenas cinco dos seis animais avaliados voltaram a completar seu ciclo estral. Neste caso, o animal 78 não completou seu ciclo nos meses de verão.

As éguas apresentaram uma onda folicular maior e primária durante o ciclo estral. Não houve ocorrência de dupla ovulação para as éguas desta raça.

O maior tamanho obtido pela estrutura lútea foi identificado no terceiro dia após a ovulação e estava associado a tonicidade uterina grau 2 (turgido), em todas as estações 
do ano. No momento pré ovulatório, 24 horas antes da ovulação, o edema uterino apresentado foi grau 3 ( com pregas endometriais visíveis), em todas as estações (Figura 12).

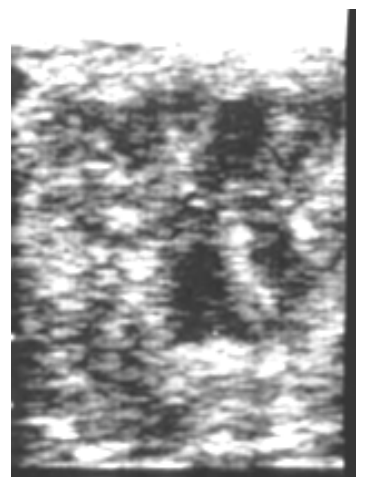

Figura 12. Edema uterino grau 3.

Fonte: Arquivo pessoal

O escore corporal variou entre 4 (moderadamente magro) e 5 (moderado).

\section{DISCUSSÃO}

O aumento da duração do ciclo estral nos meses de Inverno é justificável devido a redução da incidência luminosa, que aumenta a produção de melatonina pela glândula Pineal e como consequência gera a redução da liberação dos hormônios gonadotróficos.

Os meses de Primavera são tidos como fase de transição Vernal, no final desta muitos animais já estão aptos para aumentarem o crescimento folicular e então darem início a fase de melhor eficiência reprodutiva, o Verão. No entanto, neste Estudo, durante meses de Verão apenas cinco das seis éguas estavam aptas a reprodução. Fatores como nutrição, genética, temperatura, pastagem podem ter interferido de forma negativa sobre este exemplar .

Segundo Ginther et al (2004) e Affleck et al (1991), os períodos transicionais (Outono e Primavera) e o período contra estacional (Inverno) afetam principalmente a fase folicular. Uma vez que é preciso um maior período de exposição ao estímulo para alcançar a produção hormonal necessária e então, estimular o momento do desvio folicular, da dominância e até mesmo a ovulação.

Esta análise justifica as diferenças entre as estações sobre o dia de divergência, o dia da dominância e sobre o tamanho folicular na dominância.

Outro fator relevante que pode interferir na dinâmica folicular e na redução do período de anestro na fase transicional é a presença do garanhão. Wepsi et al (2014), mostra que a exposição da égua, em anestro transicional, a um garanhão aumenta a fecundidade e 
com isto a quantidade de tentativas reprodutivas. Neste estudo, as éguas não foram expostas aos rufiões, esta tentativa poderia ter elevado a quantidade de animais em reprodução nas estações.

A iluminação artificial é conhecida como a forma mais comum de reduzir os intervalos de anestro entre as estações (Scraba e Ginther, 1985), neste estudo, as éguas também não foram expostas a este tipo de intervenção.

Pastagens deficientes e éguas de idade avançada são causas conhecidas de prolongamento de ciclo estral, atraso a ovulação, prolongamento do anestro (Carnelave et al, 1997).

O tamanho do folículo pré ovulatório não apresentou diferença $(\mathrm{P} \geq 0,05)$ na comparação de médias entre as estações do ano, entretanto, o valor apresentado é inferior ao encontrado por Cuervo - Arango e Newcombe (2008) que indicaram folículos pré ovulatórios de $46 \mathrm{~mm}$ em éguas com ovulação espontânea; e se aproxima do resultado encontrado por Ginther et al (2008) que aponta como $40 \mathrm{~mm}$ o tamanho de folículos pré ovulatórios em éguas adultas.

O edema uterino no momento pré ovulatório, 24 horas antes da ovulação, foi máximo (grau 3- com pregas endometriais visíveis) em todas as estações do ano.

A manutenção do bom escore corporal durante todas as estações do ano mostram que os animais se adaptaram bem as forrageiras oferecidas. No entanto, a possibilidade de interferência nutricional não pode ser excluída, uma vez que o valor nutricional da forrageira está diretamente relacionado com a reprodução. E não somente a manutenção da condição corporal. 


\section{CONCLUSÃO}

As éguas da raça Campeiro apresentaram pouca interferência sazonal, já que a maioria das éguas estava cíclicas durante as estações do ano. No entanto, a utilização de técnicas que reduzam o intervalo de anestro (ex.: iluminação e rufiação) pode otimizar a utilização destes animais na reprodução.

As éguas Campeiro possuem padrão racial próximo ao de éguas adultas de porte médio. 


\section{REFERÊNCIAS BIBLIOGRÁFICAS}

AFFLECK K.J; CONBOY H.S; FITZGERALD B.P. A negative feedback role for the ovaries of the mare on tonic LH secretion before the first ovulation of the breeding season. Journal of Reproduction and Fertility, v. 44, p.241-247, 1991.

BRINSKO, S.P; BLANCHARD, T.L; SCHUMACHER, J; HINRICHER, K; VARNER, D.D; LOVE, C.C; HARTMAN, D. Manual of equine reproduction, $3^{\circ}$ edição, Ed. Elsevier, 2011.

CARNEVALE, E.M.; HERMENEL, M.J.; T, GINTHER O.J. Age and pasture effects on vernal transition in mares. Theriogenology, v 47 pg.1004-1018, 1997

CUERVO-ARANGO, J.; NEWCOMBE, J. R. Repeatability of preovulatory follicular diameter and uterine edema pattern in two consecutive cycles in the mare and how they are influenced by ovulation inductors. Theriogenology, v. 69, p.681-687, 2008

FAZENDA ÁGUA LIMPA - UnB. Resumo Anual de Dados Agrometereolóicos, 2012.

GINTHER, O. J; BEG, M. A; GASTAL M.O; GASTAL E.L. Seasonal influence on equine follicle dynamics. Animal Reproduction, v.1, p.31-44, 2004.

GINTHER, O. J; BEG, M. A; GASTAL M.O; GASTAL, E. L. Follicle dynamics and selection in mares. Animal Reproduction, v.1, p.45-63, 2004.

MCMANUS, C; FALÇÃO, R.A; SPRITZE, A; REZENDE, M.J.M; GARCIA, A.S. Caracterização Morfológica de Eqüinos da Raça Campeiro, Revista Brasileira de Zootecnia, v.34, p. $1553-1562,2005$.

RAZA, T.; CARLEYB, S.; CARD, C. Comparison of the effects of eFSH and deslorelin treatment regimes on ovarian stimulation and embryo production of donor mares in early vernal transition. Theriogenology, v.71, p.1358-1366, 2009.

SCRABA, S. T.; O. J. GINTHER. Effects of lighting program s on onset of The ovulatory season in mares. Theriogenology,v.24,1985. 
WESPIA B.; SIEMEB H.; WEDEKINDC C.; BURGER D., Exposure to stallion accelerates the onset of mares cyclicity. Theriogenology, v.82, p.189-194, 2014. 


\section{CAPÍTULO 4 - CONSIDERAÇÕES FINAIS}

Os resultados apresentados são de grande importância para os centros de conservação de recursos genéticos animais, uma vez que as raças de equinos apresentadas possuem um efetivo populacional reduzido, em especial a raça Campeiro, e associam diversas características adaptativas de interesse.

Para as duas raças a maioria dos animais se mantiveram cíclicos o ano todo, sem qualquer tipo de interferência com relação a iluminação ou alimentação, esta informação para a reprodução assistida em equinos é de grande importância, pois mostra a possibilidade de manter estes animais em reprodução o ano todo sem que tenha aumento de custos com iluminação artificial e outros.

O levantamento de dados reprodutivos permite aprimorar as biotécnicas de reprodução assistida com estes animais, como a inseminação artificial, transferência de embriões, e outras.

A caracterização de dados que envolvam estas raças de equinos é fundamental para auxiliar a fomentar o banco de germoplasma brasileiro. 